\title{
The Booms and Busts of Beta Arbitrage*
}

\author{
Shiyang Huang \\ University of Hong Kong \\ Email: huangsy@hku.hk \\ Dong Lou \\ London School of Economics and CEPR \\ Email: d.lou@lse.ac.uk \\ Christopher Polk \\ London School of Economics and CEPR \\ Email: c.polk@lse.ac.uk
}

This Draft: August 2015

First Draft: August 2013

\begin{abstract}
* We would like to thank Nicholas Barberis, Sylvain Champonnais, Andrea Frazzini, Pengjie Gao, Emmanuel Jurczenko, Toby Moskowitz, Lasse Pedersen, Emil Siriwardane, Dimitri Vayanos, Michela Verardo, Tuomo Vuolteenaho, and seminar participants at University of Cambridge, London School of Economics, Norwegian School of Economics, University of Rotterdam, University of Warwick, 2014 China International Conference in Finance, 2014 Imperial College Hedge Fund conference, 2014 Quantitative Management Initiative conference, and the 2015 American Finance Association conference, 2015 Financial Intermediation Research Society conference for helpful comments and discussions. We are grateful for funding from the Europlace Institute of Finance, the Paul Woolley Centre at the London School of Economics, and the QUANTVALLEY/FdR: Quantitative Management Initiative.
\end{abstract}




\title{
The Booms and Busts of Beta Arbitrage
}

\begin{abstract}
Low-beta stocks deliver high average returns and low risk relative to high-beta stocks, an opportunity for professional investors to "arbitrage" away. We argue that betaarbitrage activity instead generates booms and busts in the strategy's abnormal trading profits. In times of low activity, the beta-arbitrage strategy exhibits delayed correction, taking up to three years for abnormal returns to be realized. In stark contrast, when activity is high, prices overshoot as short-run abnormal returns are much larger and then revert in the long run. We document a novel positive-feedback channel operating through firm-level leverage that facilitates these boom and bust cycles.
\end{abstract}




\section{Introduction}

The trade-off of risk and return is a key concept in modern finance. The simplest and most intuitive measure of risk is market beta - the slope in the regression of a security's return on the market return. In the Capital Asset Pricing Model (CAPM) of Sharpe (1964) and Lintner (1965), market beta is the only risk needed to explain expected returns. More specifically, the CAPM predicts that the relation between expected return and beta, the security market line, has an intercept equal to the risk-free rate and a slope equal to the equity premium.

However, empirical evidence indicates that the security market line is too flat on average (Black 1972, Frazzini and Pedersen, 2014) and especially so during times of high expected inflation (Cohen, Polk, and Vuolteenaho 2005), disagreement (Hong and Sraer 2014) and market sentiment (Antoniou, Doukas, and Subrahmanyam 2013). These patterns are not explained by other well-known asset pricing anomalies such as size, value, and price momentum.

We study the response of arbitrageurs to this failure of the Sharpe-Lintner CAPM in order to identify booms and busts of beta arbitrage. In particular, we exploit the novel measure of arbitrage activity introduced by Lou and Polk (2014). They argue that traditional measures of such activity are flawed, poorly measuring a portion of the inputs to the arbitrage process, for a subset of arbitrageurs. Lou and Polk's innovation is to measure the outcome of the arbitrage process, namely, the correlated price impacts that previous research has shown can generate excess return comovement in the spirit of Barberis and Shleifer (2003). ${ }^{1}$

${ }^{1}$ See, for example, Barberis, Shleifer and Wurgler (2005), Greenwood and Thesmar (2011), Lou (2012) and Anton and Polk (2014). 
We first confirm that our measure of the excess return comovement, relative to a benchmark asset pricing model, of beta-arbitrage stocks $(C o B A R)$ is correlated with existing measures of arbitrage activity. In particular, we find that time variation in the level of institutional holdings in low-beta stocks (i.e., stocks in the long leg of the beta strategy), the assets under management of long-short equity hedge funds, and aggregate liquidity together forecast/explain roughly $38 \%$ of the time-series variation in CoBAR. These findings suggest that not only is our measure consistent with existing proxies for arbitrage activity but also that no one single existing proxy is sufficient for capturing time-series variation in arbitrage activity. Indeed, one could argue that perhaps much of the unexplained variation in $C o B A R$ represents variation in arbitrage activity missed by existing measures.

After validating our measure in this way, we then forecast the cumulative abnormal returns to beta arbitrage. We first find that when arbitrage activity is relatively high (as identified by the $20 \%$ of the sample with the highest values of CoBAR), abnormal returns to beta-arbitrage strategies occur relatively quickly, within the first six months of the trade. In contrast, when arbitrage activity is relatively low (as identified by the $20 \%$ of the sample with the lowest values of $\operatorname{CoBAR}$ ), abnormal returns to beta-arbitrage strategies take much longer to materialize, appearing only two to three years after putting on the trade.

These effects are both economically and statistically significant. When betaarbitrage activity is low, the abnormal four-factor returns on beta arbitrage are statistically insignificant from zero in the six months after portfolio formation. For the patient arbitrageur, in year 3, the strategy earns abnormal three-factor returns of $0.85 \%$ 
per month with a $t$-statistic of 2.95. In stark contrast, for those periods when arbitrage activity is high, the abnormal three-factor returns to beta arbitrage average $1.56 \%$ per month with a $t$-statistic of 3.09 in the six months after the trade. Indeed, the return differential in the first six months between high and low CoBAR periods is $1.19 \%$ per month with a $t$-statistic of 2.14 .

We then show that the stronger performance of beta-arbitrage activities during periods of high beta-arbitrage activity can be linked to subsequent reversal of those profits. In particular, the year 3 abnormal three-factor returns are $-0.74 \%$ with an associated $t$-statistic of -2.15 . As a consequence, the long-run reversal of beta-arbitrage returns varies predictably through time in a striking fashion. The post-formation, year-3 spread in abnormal returns across periods of low arbitrage activity, when abnormal returns are predictably positive, and periods of high arbitrage activity, when abnormal returns are predictably negative, is $-1.60 \% /$ month $(t$-statistic $=-3.29)$ or more than $19 \%$ cumulative in that year. These short- and long-run return differentials across high and low CoBAR periods barely change if we also control for exposure to the Carhart (1997) momentum factor.

Our results reveal interesting patterns in the relation between arbitrage returns and arbitrage crowd. When beta-arbitrage activity is low, the returns to beta-arbitrage strategies exhibit significant delayed correction. In contrast, when beta-arbitrage activity is high, the returns to beta-arbitrage activities reflect strong over-correction due to crowded arbitrage trading. These results are consistent with time-varying arbitrage activity generating booms and busts in beta arbitrage. 
We argue that these results are intuitive, as it is difficult to know how much arbitrage activity is pursuing beta arbitrage, and, in particular, the strategy is susceptible to positive-feedback trading. Specifically, successful bets on (against) lowbeta (high-beta) stocks result in prices for those securities rising (falling). If the underlying firms are leveraged, this change in price will, all else equal, result in the security's beta falling (increasing) further. Thus, not only do arbitrageurs not know when to stop trading the low-beta strategy, their (collective) trades strengthen the signal. Consequently, beta arbitrageurs may increase their bets precisely when trading is more crowded. ${ }^{2}$

Consistent with our novel positive-feedback story, we show that the crosssectional spread in betas increases when beta-arbitrage activity is high and particularly so when beta-arbitrage stocks are relatively more levered. As a consequence, stocks remain in the extreme beta portfolios for a longer period of time. Our novel positive feedback channel also has implications for cross-sectional heterogeneity in abnormal returns; we find that our boom and bust beta-arbitrage cycles are particularly strong among high-leverage stocks.

A variety of robustness tests confirm our main findings. In particular, we show that controlling for other factors when either measuring CoBAR or when predicting betaarbitrage returns does not alter our primary conclusions a) that the excess comovement of beta-arbitrage stocks forecasts time-varying reversal to beta-arbitrage bets and b) that the beta spread varies with $C o B A R$.

\footnotetext{
${ }^{2}$ Note that crowded trading may or may not be profitable, depending on how long the arbitrageur holds the position and how long it takes for any subsequent correction to occur.
} 
Our findings can also be seen by estimating time variation in the short-run (months 1-6) and long-run (year 3) security market lines, conditioning on CoBAR. Thus, the patterns we find are not just due to extreme-beta stocks, but reflect dynamic movements throughout the entire cross section. In particular, we find that during periods of high beta-arbitrage activity, the short-term security market line strongly slopes downward, indicating strong profits to the low-beta strategy, consistent with arbitrageurs expediting the correction of market misevaluation. However, this correction is excessive, as the long-run security market line dramatically slopes upwards. In contrast, during periods of low beta-arbitrage activity, the short-term security market line is weakly upward sloping. During these low-arbitrage periods, we do not find any downward slope to the security market line until the long-run.

A particularly compelling robustness test involves separating CoBAR into excess comovement among low-beta stocks occurring when these stocks have relatively high returns (i.e., capital flowing into low beta stocks and pushing up the prices) vs. excess comovement occurring when low-beta stocks have relatively low returns-i.e., upside versus downside comovement. Under our interpretation of the key findings, it is the former that should track time-series variation in expected beta-arbitrage returns, as that particular direction of comovement is consistent with trading aiming to correct the beta anomaly. Our evidence confirms this indeed is the case: our main results are primarily driven by upside $C O B A R$.

Finally, Shleifer and Vishny (1997) link the extent of arbitrage activity to limits to arbitrage. Based on their logic, trading strategies that bet on firms that are cheaper to arbitrage (e.g., larger stocks, more liquid stocks, or stocks with lower idiosyncratic 
risk) should have more arbitrage activity. This idea of limits to arbitrage motivates tests examining cross-sectional heterogeneity in our findings. We show that our results primarily occur in those stocks that provide the least limits to arbitrage: large stocks, liquid stocks, and stocks with low idiosyncratic volatility. This cross-sectional heterogeneity in the effect is again consistent with the interpretation that arbitrage activity causes much of the time-varying patterns we document.

The organization of our paper is as follows. Section II summarizes the related literature. Section III describes the data and empirical methodology. We detail our empirical findings in section IV, and present some additional results in Section V. Section VI concludes.

\section{Related Literature}

Our results shed new light on the risk-return trade-off, a cornerstone of modern asset pricing research. This trade-off was first established in the Sharpe-Lintner CAPM, which argues that the market portfolio is mean-variance-efficient. Consequently, a stock's expected return is a linear function of its market beta, with a slope equal to the equity premium and an intercept equal to the risk-free rate.

However, mounting empirical evidence is inconsistent with the CAPM. Black, Jensen, and Scholes (1972) were the first to show carefully that the security market line is too flat on average. Put differently, the risk-adjusted returns of high beta stocks are too low relative to those of low-beta stocks. This finding was subsequently confirmed in an influential study by Fama and French (1992). Blitz and van Vliet (2007) and Baker, Bradley, and Taliaferro (2013), Frazzini and Pedersen (2014), and Blitz, Pang, and van 
Vliet (2012) document that the low-beta anomaly is also present in both non-US developed markets as well as emerging markets.

Of course, the flat security market line is not the only failing of the CAPM (see Fama and French 1992, 1993, and 1996). Nevertheless, since this particular issue is so striking, a variety of explanations have been offered to explain the low-beta phenomenon. Black (1972) and more recently Frazzini and Pedersen (2014) argue that leverage-constrained investors, such as mutual funds, tend to deviate from the capital market line and invest in high beta stocks to pursue higher expected returns, thus causing these stocks to be overpriced relative to the CAPM benchmark. ${ }^{3}$

Cohen, Polk, and Vuolteenaho (2005) derive the cross-sectional implications of the CAPM in conjunction with the money illusion story of Modigliani and Cohn (1979). They show that money illusion implies that, when inflation is low or negative, the compensation for one unit of beta among stocks is larger (and the security market line steeper) than the rationally expected equity premium. Conversely, when inflation is high, the compensation for one unit of beta among stocks is lower (and the security market line shallower) than what the overall pricing of stocks relative to bills would suggest. Cohen, Polk, and Vuolteenaho provide empirical evidence in support of their theory.

Hong and Sraer (2014) provide an alternative explanation based on Miller's (1977) insights. In particular, they argue that investors disagree about the value of the market portfolio. This disagreement, coupled with short sales constraints, can lead to overvaluation, and particularly so for high-beta stocks, as these stocks allow optimistic

${ }^{3}$ See also Baker, Bradley, and Wurgler (2011) and Buffa, Vayanos, and Woolley (2014) for related explanations based on benchmarking of institutional investors. 
investors to tilt towards the market. Further, Kumar (2009) and Bali, Cakici, and Whitelaw (2011) show that high risk stocks can indeed underperform low risk stocks, if some investors have a preference for volatile, skewed returns, in the spirit of the cumulative prospect theory as modeled by Barberis and Huang (2008). Related work also includes Antoniou, Doukas, and Subrahmanyam (2013). ${ }^{4}$

A natural question is why sophisticated investors, who can lever up and sell short securities at relatively low costs, do not fully take advantage of this anomaly and thus restore the theoretical relation between risk and returns. Our paper is aimed at addressing this exact question. Our premise is that professional investors indeed take advantage of this low-beta return pattern, often in dedicated strategies that buy lowbeta stocks and sell high-beta stocks. However, the amount of capital that is dedicated to this low-beta strategy is both time varying and unpredictable from arbitrageurs' perspectives, thus resulting in periods where the security market line remains too flati.e., too little arbitrage capital, as well as periods where the security market line becomes overly steep-i.e., too much arbitrage capital.

Not all arbitrage strategies have these issues. Indeed, some strategies have a natural anchor that is relatively easily observed (Stein 2009). For example, it is straightforward to observe the extent to which an ADR is trading at a price premium (discount) relative to its local share. This ADR premium/discount is a clear signal to an arbitrageur of an opportunity and, in fact, arbitrage activity keeps any price differential

\footnotetext{
${ }^{4}$ In addition, Campbell, Giglio, Polk, and Turley (2015) document that high-beta stocks hedge timevariation in the aggregate market's return volatility, offering a potential explanation for the low-beta anomaly.
} 
small with deviations disappearing within minutes. ${ }^{5}$ Importantly, if an unexpectedly large number of ADR arbitrageurs pursue a particular trade, the price differential narrows. An individual ADR arbitrageur can then adjust his or her demand accordingly.

There is, however, no easy anchor for beta arbitrage. ${ }^{6}$ Further, we argue that the difficulty in identifying the amount of beta-arbitrage capital is exacerbated by an indirect positive-feedback channel. ${ }^{7}$ Namely, beta-arbitrage trading can lead to the cross-sectional beta spread increasing when firms are levered. As a consequence, stocks in the extreme beta deciles are more likely to remain in these extreme groups when arbitrage trading becomes excessive. Given that beta arbitrageurs rely on realized beta as their trading signal, this beta expansion resulting from leverage effectively causes a potential feedback loop in the beta-arbitrage strategy.

\section{Data and Methodology}

The main dataset used in this study is the stock return data from the Center for Research in Security Prices (CRSP). Following prior studies on the beta-arbitrage strategy, we include in our study all common stocks on NYSE, Amex, and NASDAQ. We then augment this stock return data with institutional ownership in individual

\footnotetext{
${ }^{5}$ Rösch (2014) studies various properties of ADR arbitrage. For his sample of 72 ADR home stock pairs, the average time it takes until a ADR/home stock price deviation disappears is 252 seconds. For an institutional overview of this strategy, see J.P. Morgan (2014).

${ }^{6}$ Polk, Thompson, and Vuolteenaho (2006) use the Sharpe-Lintner CAPM to relate the cross-sectional beta premium to the equity premium. They show how the divergence of the two types of equity-premium measures implies a time-varying trading opportunity for beta arbitrage. Their methods are quite sophisticated and produce signals about the time-varying attractiveness of beta-arbitrage that, though useful in predicting beta-arbitrage returns, are still, of course, quite noisy.

7 The idea that positive-feedback strategies are prone to destabilizing behaviour goes back to at least DeLong, Shleifer, Summers, and Waldmann (1990). In contrast, negative-feedback strategies like ADR arbitrage or value investing are less susceptible to destabilizing behaviour by arbitrageurs, as the price mechanism mediates any potential congestion. See Stein (2009) for a discussion of these issues.
} 
stocks provided by Thompson Financial. We further obtain information on assets under management of long-short equity hedge funds from Lipper's Trading Advisor Selection System (TASS). Since the assets managed by hedge funds grow substantially in our sample period, we detrend this variable.

We also construct, as controls, a list of variables that have been shown to predict future beta-arbitrage strategy returns. Specifically, a) following Cohen, Polk, and Vuolteenaho (2005), we construct an expected inflation index, defined as the exponential moving average CPI growth rate over the past 100 months (where the weight on month $\mathrm{N}$ is given by $2 /(\mathrm{n}+1))$; b) we also include in our study the sentiment index proposed by Baker and Wurgler (2006, 2007); c) following Hong and Sraer (2014), we construct an aggregate disagreement proxy as the beta-weighted standard deviation of analysts' long-term growth rate forecasts; finally, following Frazzini and Pedersen (2014), we use the Ted spread-the difference between the LIBOR rate and the US Treasury bill rate - as a measure of financial intermediaries' funding constraints.

We begin our analysis in 1970, as that year was when the low-beta anomaly was first recognized by academics. ${ }^{8}$ At the end of each month, we sort all stocks into deciles (in some cases vigintiles) based on their pre-ranking market betas. Following prior literature, we calculate pre-ranking betas using daily returns in the past twelve months. (Our results are similar if we use monthly returns, or different pre-ranking periods.) To account for illiquidity and non-synchronous trading, we include on the right hand side of the regression equation five lags of the excess market return, in addition to the

\footnotetext{
${ }^{8}$ Though eventually published in 1972, Black, Jensen, and Scholes had been presented as early as August of 1969. Mehrling (2005) biography of Fischer Black details the early history of the low-beta anomaly.
} 
contemporaneous excess market return. The pre-ranking beta is simply the sum of the six coefficients from the OLS regression.

We then compute pairwise partial correlations using 52 weekly returns for all stocks in each decile in the portfolio ranking period. We control for the Fama-French three factors when computing these partial correlations to purge out any comovement in stocks induced by known risk factors. We measure the excess comovement of stocks involved in beta arbitrage $(C o B A R)$ as the average pairwise partial correlation in the lowest market beta decile. We focus on the low-beta decile as these stocks tend to be larger, more liquid, and have lower idiosyncratic volatility compared to the high-beta decile; thus, our measurement of excess comovement will be less susceptible to issues related to asynchronous trading and measurement noise. ${ }^{9}$ We operationalize this calculation by computing the average correlation of the three-factor residual of every stock in the lowest beta decile with the rest of the stocks in the same decile:

$$
\operatorname{CoBAR}=\frac{1}{N} \sum_{i=1}^{N} \operatorname{partialCorr}\left(\operatorname{retr} f_{i}^{L}, \operatorname{retrf}_{-i}^{L} \mid \operatorname{mktrf}, \operatorname{smb}, h m l\right),
$$

where $\operatorname{retrf}_{i}^{L}$ is the weekly return of stock $i$ in the (L)owest beta decile, $\operatorname{retr} f_{-i}^{L}$ is the weekly return of the equal-weight lowest beta decile excluding stock $i$, and $N$ is the number of stocks in the lowest beta decile. We have also measured CoBAR using returns that are orthogonalized not only to the Fama-French factors but also to each stock's industry return or to other empirical priced factors, and our conclusions continue to hold. We present these and many other robustness tests in Table IV.

\footnotetext{
${ }^{9}$ Our results are robust to measuring $\operatorname{CoBAR}$ using a pooled sample of high- and low-beta stocks (putting a negative sign in front of the returns of high-beta stocks), as well as the (minus) cross-correlation between high- and low-beta deciles.
} 
In the following period, we then form a zero-cost portfolio that goes long the valueweight portfolio of stocks in the lowest market beta decile and short the value-weight portfolio of stocks in the highest market beta decile. We track the cumulative abnormal returns of this zero-cost long-short portfolio in months 1 through 36 after portfolio formation. To summarize the timing of our empirical exercise, year 0 is our portfolio formation year (during which we also measure $\operatorname{CoBAR}$ ), year 1 is the holding year, and years 2 and 3 are our post-holding period, to detect any (conditional) long-run reversal to the beta-arbitrage strategy.

\section{Main Results}

We first document simple characteristics of our arbitrage activity measure. Table I Panel A indicates that there is significant excess correlation among low-beta stocks on average and that this pairwise correlation varies through time. Specifically, the mean of CoBAR is 0.11 varying from a low of 0.03 to a high of 0.20 .

Panel B of Table I examines CoBAR's correlation with existing measures linked to time variation in the expected abnormal returns to beta-arbitrage strategies. We find that $\operatorname{CoBAR}$ is high when disagreement is high, with a correlation of 0.34 . CoBAR is also positively correlated with the Ted spread, consistent with a time-varying version of Black (1972), though the Ted spread does not forecast time-variation in expected abnormal returns to beta-arbitrage strategies (Frazzini and Pederson 2014). CoBAR is negatively correlated with the expected inflation measure of Cohen, Polk, and Vuolteenaho. However, in results not shown, the correlation between expected inflation and CoBAR becomes positive for the subsample from 1990-2010, consistent with 
arbitrage activity eventually taking advantage of this particular source of time-variation in beta-arbitrage profits. There is little to no correlation between $C o B A R$ and sentiment.

Figure 1 plots CoBAR as of the end of each December. Note that we do not necessarily expect a trend in this measure. Though there is clearly more capital invested in beta-arbitrage strategies, in general, markets are also more liquid. Nevertheless, after an initial spike in 1972, CoBAR trends slightly upward for the rest of the sample. However, there are clear cycles around this trend. These cycles tend to peak before broad market declines. Also, note that CoBAR is essentially uncorrelated with market volatility. A regression of CoBAR on contemporaneous realized market volatility produces a loading of -0.23 with a $t$-statistic of -0.79 .

Consistent with our measure tracking arbitrage activity, CoBAR is persistent through time. The autocorrelation of non-overlapping December observations is 0.1. Appendix Table A1 documents that CoBAR is also persistent in event time. Specifically, the correlation between $\operatorname{CoBAR}$ measured in year 0 and year 1 for the same set of stocks is 0.29. In fact, year-0 CoBAR remains highly correlated with subsequent values of CoBAR for the same stocks all the way out to year 3. The average value of CoBAR remains high as well. Recall that in year 0 , the average excess correlation is 0.11 . We find that in years 1,2, and 3, the average excess correlation of these same stocks remains around $0.07 .{ }^{10}$

${ }^{10}$ CoBAR is essentially uncorrelated with a similar measure of excess comovement based on the fifth and sixth beta deciles. 


\section{IV.A. Determinants of CoBAR}

To confirm that our measure of beta-arbitrage is sensible, we estimate regressions forecasting $\operatorname{CoBAR}$ with two variables that are often used to proxy for arbitrage activity. The first variable we use is the aggregate institutional ownership (Inst Own) of the lowbeta decile - i.e., stocks in the long leg of the beta strategy-based on $13 \mathrm{~F}$ filings. We include institutional ownership as these investors are typically considered smart money, at least relative to individuals, and we focus on their holdings in the low-beta decile as we do not observe their short positions in the high-beta decile. We also include the assets under management $(A U M)$ of long-short equity hedge funds, the prototypical arbitrageur.

All else equal, we expect $\operatorname{CoBAR}$ to be lower if markets are more liquid. However, as arbitrage activity is endogenous, times when markets are more liquid may also be times when arbitrageurs are more active. Indeed, Cao, Chen, Liang, and Lo (2013) show that hedge funds increase their activity in response to increases in aggregate liquidity. Following Cao, Chen, Liang, and Lo, we further include past market liquidity as proxied by the Pastor and Stambaugh (2003) liquidity factor (PS liquidity) in our regressions to measure which channel dominates.

All regressions in Table II include a trend to ensure that our results are not spurious. We also report specifications that include variables that arguably should forecast beta-arbitrage returns: the inflation, sentiment, and disagreement indices as well as the Ted spread. We measure these variables contemporaneously with CoBAR as we will be running horse races against these variables in our subsequent analysis. 
Regression (2) in Table II documents that all three variables (Inst Own, AUM, and PS liquidity) forecast $\operatorname{CoBAR}$, with an $\mathrm{R}^{2}$ of approximately $38 \%{ }^{11}$ Regressions (3) and (4) show that the extant predictors of beta-arbitrage returns are not highly correlated with CoBAR. Only one potential predictor of beta-arbitrage profitability, the Ted spread, adds some incremental explanatory power, with the sign of the coefficient consistent with arbitrageurs taking advantage of potential time-variation in betaarbitrage returns linked to this channel. Indeed, as we show later, the Ted spread does a poor job forecasting beta-arbitrage returns in practice, perhaps because arbitrageurs have compensated appropriately for this potential departure from Sharpe-Lintner pricing.

Overall, these findings make us comfortable in our interpretation that CoBAR is related to arbitrage activity and distinct from existing measures of opportunities in beta arbitrage. As a consequence, we turn to the main analysis of the paper, the short- and long-run performance of beta-arbitrage returns, conditional on CoBAR.

\section{IV.B. Forecasting Beta-Arbitrage Returns}

Table III forecasts the abnormal returns on the standard beta-arbitrage strategy as a function of investment horizon, conditional on CoBAR. Panel A examines Fama and French (1993) three-factor-adjusted returns while Panel B studies abnormal returns relative to the four-factor model of Carhart (1997). In each panel, we measure the average abnormal returns in the first six months subsequent to the beta-arbitrage trade,

\footnotetext{
${ }^{11}$ We choose to forecast $C O B A R$ in predictive regressions rather than explain $C O B A R$ in contemporaneous regressions simply to reduce the chance of a spurious fit. However, Appendix Table A2 shows that $R^{2} \mathrm{~S}$ remain high in contemporaneous versions of these regressions.
} 
and those occurring in years one, two, and three. These returns are measured conditional on the value of $C o B A R$ as of the end of the beta formation period. In particular, we split the sample into five $\operatorname{CoBAR}$ quintiles.

Pursuing beta arbitrage when arbitrage activity is low takes patience. Abnormal three-factor returns are statistically insignificant in the first year for the bottom four CoBAR groups. Abnormal returns only become statistically significant for the two lowest CoBAR groups in the second year. This statistical significance continues through year 3 for the $20 \%$ of the sample where beta-arbitrage activity is at its lowest values.

These findings continue to hold if we also adjust for the momentum effect. In Panel B, four-factor beta-arbitrage alphas are indistinguishable from zero except in year 3 for the lowest $\operatorname{CoBAR}$ group. In that period, the four-factor alpha is $0.54 \% /$ month with an associated $t$-statistic of $2.03 .^{12}$

However, as beta-arbitrage activity increases, the abnormal returns arrive sooner and stronger. For the highest $\operatorname{CoBAR}$ group, the abnormal four-factor returns average $1.19 \% /$ month in the six months immediately subsequent to the beta-arbitrage trade. This finding is statistically significant with a $t$-statistic of 2.34. Moreover, the difference between abnormal returns in high and low $\operatorname{CoBAR}$ periods is $1.16 \% /$ month with a $t$ statistic of 2.08 .

The key finding of our paper is that these quicker and stronger beta-arbitrage returns can be linked to subsequent reversal in the long run. Specifically, in year three, the abnormal four-factor return to beta arbitrage when CoBAR is high is $-1.04 \% /$ month,

\footnotetext{
${ }^{12}$ We have also separately examined the long and short legs of beta arbitrage (i.e., low-beta vs. high-beta stocks). Around $40 \%$ of our return effect comes from the long leg, and the remaining $60 \%$ from the short leg.
} 
with a $t$-statistic of -3.12 . These abnormal returns are dramatically different from their corresponding values when $\operatorname{CoBAR}$ is low; the difference in year 3 abnormal four-factor returns is $-1.58 \% /$ month $(t$-statistic $=-3.33)$.

Figure 2 summarizes these patterns by plotting the cumulative abnormal fourfactor returns to beta arbitrage during periods of high and low CoBAR. This figure clearly shows that there is a significant delay in abnormal trading profits to beta arbitrage when beta-arbitrage activity is low. However, when beta-arbitrage activity is high, beta arbitrage results in prices overshooting, as evidenced by the long-run reversal we document. We argue that trading of the low-beta anomaly is initially stabilizing, then, as the trade becomes crowded, turns destabilizing, causing prices to overshoot. ${ }^{13}$

\section{IV.C. Robustness of Key Results}

Table IV examines variations to our methodology to ensure that our finding of timevarying reversal of beta-arbitrage profits is robust. For simplicity, we only report the difference in returns to the beta strategy between the high and low CoBAR groups in the short run (months 1-6) and the long-run (year 3). For reference, the first row of Table IV reports the baseline results from Table III Panel B.

In row two, we conduct the same analysis for the sub-period before our sample (1927-1969). Of course, this sample not only predates the discovery of the low-beta anomaly but also is a period where there is much less arbitrage activity in general, at least explicitly organized as such. Thus, this period could be thought of as a placebo test

\footnotetext{
${ }^{13}$ We postpone the discussion of conditional abnormal returns to beta arbitrage (as shown in the last row of Table II) to Section V.C.
} 
of our story. Consistent with our paper's explanation, we find no statistically significant link between $C o B A R$ and beta-arbitrage returns.

Our remaining subsample analysis excludes potential outlier years. We find that our results remain robust if we exclude the tech bubble crash (2000-2001) or the recent financial crisis (2007-2009) from our sample.

In rows five through eight, we report the results from similar tests using extant variables linked to potential time variation in beta-arbitrage profits. None of the four variables are associated with time variation in long-run abnormal returns. Thus, our CoBAR measure has not simply repackaged an effect linked to an existing forecasting variable.

In rows nine through 16, we consider alternative definitions of CoBAR. In the ninth row, we control for UMD when computing CoBAR. In row 10, we separate HML into its large cap and small cap components. In Row 11, we report results based on Fama and French (2015a, 2015b) five-factor returns. In Row 12, we perform the entire analysis on an industry-adjusted basis by sorting stocks into beta deciles within industries. Row 13 uses the correlation between the high-beta and low-beta deciles as a measure of arbitrage activity, with lower values indicating more activity. ${ }^{14}$

Rows 14 and 15 split CoBAR into upside and downside components. Specifically, we measure the following

$$
\operatorname{CoBAR} R^{U}=\frac{1}{N} \sum_{i=1}^{N} \operatorname{partialCorr}\left(\operatorname{retr}_{i}^{L}, \operatorname{retrf}_{-i}^{L} \mid \operatorname{mktrf}, \operatorname{smb}, h m l, \operatorname{retrf} f^{L}>\operatorname{median}\left(\operatorname{retrf} f^{L}\right)\right)
$$

\footnotetext{
${ }^{14}$ We also compute CoBAR based on a pooled sample of high- and low-beta stocks, putting a negative sign in front of the returns of high-beta stocks. The results are similar. For example, after controlling for other confounding factors, the difference in three-factor alpha of beta arbitrage in year three after portfolio formation between high and low CoBAR periods is $-0.96 \% /$ month $(t$-statistic $=-2.24)$, and that same different in four-factor alpha is $-0.77 \% /$ month $(t$-statistic $=-1.79)$.
} 


$$
\operatorname{CoBAR} R^{D}=\frac{1}{N} \sum_{i=1}^{N} \operatorname{partialCorr}\left(\operatorname{retr}_{i}^{L}, \operatorname{retrf}_{-i}^{L} \mid \operatorname{mktrf}, \operatorname{smb}, \operatorname{hml}, \operatorname{retrf} f^{L}<\operatorname{median}\left(\operatorname{retrf}{ }^{L}\right)\right)
$$

Separating $C o B A R$ in this way allows us to distinguish between excess comovement tied to strategies buying low-beta stocks (such as those followed by beta arbitrageurs) and strategies selling low-beta stocks (such as leveraged-constrained investors modeled by Black (1972)). Consistent with our interpretation, we find that only $\operatorname{CoBAR}{ }^{U}$ forecasts time variation in the short- and long-run expected returns to beta arbitrage (whereas CoBAR $R^{D}$ does not).

Rows 16-21 document that our results are robust to replacing CoBAR with residual $C o B A R$. In particular, we orthogonalize $\operatorname{CoBAR}$ to measures of arbitrage activity in momentum and value (Lou and Polk 2014), the average correlation in the market (Pollet and Wilson 2010), the past volatility of beta-arbitrage returns, the volatility of market returns over the twelve-month period corresponding to the measurement of CoBAR, and a trend.

In all cases, CoBAR continues to predict time-variation in year 3 returns. The estimates are always economically significant, with most point estimates larger than $1 \% /$ month. ${ }^{15}$ Statistical significance is always strong as well, with most $t$-statistic larger than 3. Taken together, these results confirm that our measure of crowded beta arbitrage robustly forecasts times of strong reversal to beta-arbitrage strategies.

\footnotetext{
${ }^{15}$ Though in some instances, difference in short-run abnormal returns across high and low CoBAR periods are no longer statistically significant; the point estimates are always economically large. Moreover, some of the overcorrection corresponding to the long-run reversal may accrue in our formation period as the timing of our empirical exercise is somewhat arbitrary. It is certainly possible that the beta arbitrageurs we are interested in may use shorter formation periods when pursuing their particular version of the strategy. Also, in these instances, the peak in cumulative abnormal returns that we find does not exactly coincide with our somewhat arbitrary six-month window.
} 
In unreported results, we have also studied variation in beta-arbitrage profits linked to Inst Own (the aggregate institutional ownership of the low-beta decile), the only proxy for arbitrage activity available for the full sample, as well as the linear combination of the three variables implied by regression (2) in Table II. Institutional ownership is unable to pick up the long-run reversal we have linked to CoBAR. Interestingly, the fitted value of CoBAR from regression (2) in Table II is able to pick up some of the reversal that is key to our paper, though the effect is not statistically significant.

In Table $\mathrm{V}$, we report the results of regressions forecasting the abnormal fourfactor returns to beta-arbitrage spread bets, while controlling for other predictors of beta-arbitrage returns. Unlike Table II, these regressions exploit not just the ordinal but also the cardinal aspect of $C o B A R$. Moreover, these regressions not only confirm that our findings are robust to existing measures of the profitability of beta arbitrage, they also document the relative extent to which existing measures forecast abnormal returns to beta-arbitrage strategies in the presence of $C o B A R$.

Regressions (1)-(3) in Table $\mathrm{V}$ forecast time-series variation in abnormal betaarbitrage returns in months 1-6. Regression (1) confirms that CoBAR strongly forecasts beta-arbitrage four-factor alphas over the full sample. Regression (2) then includes controls that are available over the entire sample. These include the inflation and sentiment indices, market volatility, and a version of Cohen, Polk, and Vuolteenaho's (2003) value spread for the beta deciles in question. CoBAR continues to reliably describe time-variation in abnormal four-factor returns on the low-beta-minus-high-beta strategy, with only the sentiment index providing any additional explanatory power. 
Over the shorter sample period where both aggregate disagreement and the Ted spread are available, CoBAR retains its economic significance, but becomes marginally statistically significant in forecasting time-variation in the abnormal returns to the betaarbitrage strategy.

Regressions (4)-(6) of Table V forecast the returns on beta-arbitrage strategies in year 3. The message from these regressions concerning the main result of the paper is clear; CoBAR strongly forecasts a time-varying reversal regardless of the other forecasting variables included in the regression.

\section{IV.D. Predicting the Security Market Line}

Our results can also be seen from time variation in the shape of the security market line (SML) as a function of lagged CoBAR. Such an approach can help ensure that the timevariation we document is not restricted to a small subset of extreme-beta stocks, but instead is a robust feature of the cross-section. At the end of each month, we sort all stocks into 20 value-weighted portfolios by their pre-ranking betas. ${ }^{16}$ We track these 20 portfolio returns both in months 1-6 and months 25-36 after portfolio formation to compute short-term and long-term post-ranking betas, and, in turn, to construct our short-term and long-term security market lines.

For the months 1-6 portfolio returns, we then compute the post-ranking betas by regressing each of the 20 portfolios' value-weighted monthly returns on market excess returns. Following Fama and French (1992), we use the entire sample to compute post-

\footnotetext{
${ }^{16}$ We sort stocks into vigintiles in order to increase the statistical precision of our cross-sectional estimate. However, Appendix Table A3 confirms that our results are virtually identical if we instead sort stocks into deciles.
} 
ranking betas. That is, we pool together these six monthly returns across all calendar months to estimate the portfolio beta. We estimate post-ranking betas for months 25-36 in a similar fashion. The two sets of post-ranking betas are then labelled $\beta_{1}^{1}, \ldots, \beta_{20}^{1}$ and $\beta_{1}^{25}, \ldots, \beta_{20}^{25}$

To calculate the intercept and slope of the short-term and long-term security market lines, we estimate the following cross-sectional regressions:

$$
\begin{aligned}
& \text { short-term SML: } X \operatorname{Ret}_{i, t}^{1}=\text { intercept }_{t}^{1}+\operatorname{slope}_{t}^{1} \beta_{i}^{1}, \\
& \text { long-term SML: } X \operatorname{Ret}_{i, t}^{25}=\text { intercept }_{t}^{25}+\operatorname{slope}_{t}^{25} \beta_{i}^{25}
\end{aligned}
$$

where $X \operatorname{Ret}_{i, t}^{1}$ is portfolio $i$ 's monthly excess returns in months 1 through 6 , and $X \operatorname{Ret}_{i, t}^{25}$ is portfolio i's monthly returns in months 25 through 36 . These two regressions then give us two time-series of coefficient estimates of the intercept and slope of the shortterm and long-term security market lines: (intercept $t_{t}^{1}$, slope $\left._{t}^{1}\right)$ and $\left(\right.$ intercept $_{t}^{25}$, slope $\left._{t}^{25}\right)$, respectively. As the average excess returns and post-ranking betas are always measured at the same point in time, the pair $\left(\right.$ intercept $_{t}^{1}$, slope $\left._{t}^{1}\right)$ fully describes the security market line in the short run, while $\left(\right.$ intercept $_{t}^{25}$, slope $\left._{t}^{25}\right)$ captures $^{2}$ the security market line two years later.

We then examine how these intercepts and slopes vary as a function of our measure of beta-arbitrage capital. In particular, we conduct an OLS regression of the intercept and slope measured in each month on lagged CoBAR. As can be seen from Table VI, the intercept of the short-term security market line significantly increases in CoBAR, and its slope significantly decreases in $\operatorname{CoBAR}$. The top panel of Figure 3 shows this pattern graphically. During high $\operatorname{CoBAR}$-i.e., high beta-arbitrage capital-periods, the short-term security market line strongly slopes downward, indicating strong profits 
to the low-beta strategy, consistent with arbitrageurs expediting the correction of market misevaluation. In contrast, during low $\operatorname{CoBAR}$ - i.e., low beta-arbitrage capitalperiods, the short-term security market line is weakly upward sloping and the betaarbitrage strategy, as a consequence, unprofitable, consistent with delayed correction of the beta anomaly.

The pattern is completely reversed for the long-term security market line. The intercept of the long-term security market line is significantly negatively related to CoBAR, whereas its slope is significantly positively related to CoBAR. As can be seen from the bottom panel of Figure 3, two years after high $\operatorname{CoBAR}$ periods, the long-term security market line turns upward sloping; indeed, the slope is so steep that the beta strategy loses money, consistent with over-correction of the low beta anomaly by crowded arbitrage trading. In contrast, after low CoBAR periods, the long-term security market line turns downward sloping, reflecting eventual profitability of the low-beta strategy in the long run.

\section{Beta Expansion and Additional Analyses}

We perform a number of further analyses to provide additional support to our thesis that crowded arbitrage trading can potentially destabilize prices.

\section{V.A. Beta Expansion}

Beta arbitrage can be susceptible to positive-feedback trading. Successful bets on (against) low-beta (high-beta) stocks result in prices for those securities rising (falling). If the underlying firms are leveraged, this change in price will, all else equal, result in 
the security's beta falling (increasing) further. ${ }^{17}$ Thus, not only do arbitrageurs not know when to stop trading the low-beta strategy, their (collective) trades also affect the strength of the signal. Consequently, beta arbitrageurs may increase their bets precisely when trading becomes crowded and the profitability of the strategy has decreased.

We test this prediction in Table VII. The dependent variable in columns (1) and (2) is the spread in betas across the high and low value-weight beta decile portfolios, denoted BetaSpread, as of the end of year 1. The independent variables include lagged CoBAR, the beta-formation-period value of BetaSpread, the average book leverage quintile (Leverage) across the high and low beta decile portfolios, and an interaction between CoBAR and Leverage.

The dependent variable in columns (3) and (4) is the fraction of the stocks in the high and low beta decile portfolios that continue to be in these portfolios when stocks are resorted into beta deciles at the end of year 1 (denoted Fraction). Note that since we estimate beta using 52 weeks of stock returns, the two periods of beta estimation that determine the change in BetaSpread and Fraction do not overlap. We include a trend in all regressions, but our results are robust to not including the trend dummy.

Regression (1) in Table VII shows that when CoBAR is relatively high, future BetaSpread is also high, controlling for lagged BetaSpread. A one-standard-deviation increase in CoBAR forecasts an increase in BetaSpread of roughly 7\%. Regression (2) shows that this is particular true when Leverage is also high. If beta-arbitrage bets were to contain the highest book-leverage quintile stocks, a one-standard deviation increase in CoBAR would increase BetaSpread by nearly $10 \%$.

${ }^{17}$ The idea that, all else equal, changes in leverage drive changes in equity beta is, of course, the key insight behind Proposition II of Modigiliani and Miller (1958). 
These results are consistent with a positive feedback channel for the betaarbitrage strategy that works through firm-level leverage. In terms of the economic magnitude of this positive feedback loop, we draw a comparison with the price momentum strategy. The formation-period spread for a standard price momentum bet in the post-1963 period is around 115\%, while the momentum profit in the subsequent year is close to $12 \%$ (e.g., Lou and Polk, 2014). Put differently, if we attribute price momentum entirely to positive feedback trading, such trading increases the initial return spread by about $10 \%$ (12\% divided by $115 \%)$ in the subsequent year, which is similar in magnitude to the positive feedback channel we document for beta arbitrage.

Regressions (3) and (4) replace the dependent variable, BetaSpread, with Fraction. Together, these regressions show that a larger fraction of the stocks in the extreme-beta portfolios remain in these portfolios when CoBAR is relatively high and these portfolios are particularly levered. Specifically, a one-standard-deviation increase in CoBAR is associated with the level of Fraction increasing by 1.6\%. Regression (4) confirms that this effect is particularly strong when Leverage is also high. If betaarbitrage bets were to contain the highest book-leverage quintile stocks, a one-standard deviation increase in CoBAR would increase Fraction by more than 6\%. Table VII Panel B confirms that these results are robust to the same methodological variations as in Table IV.

Table VIII turns to firm-level regressions to document the beta expansion our story predicts. In particular, we estimate panel regressions of subsequent changes in stock beta on lagged CoBAR. At the end of each month, all stocks are sorted into deciles based on their market beta calculated using daily returns in the past 12 months. The 
dependent variable is BetaChange, the change in stock beta from year t to $t+1$ (again, we use non-overlapping periods). In addition to $\operatorname{CoBAR}$, we also include Distance, the difference between a stock's beta decile rank and the average rank of 5.5 in year t. Leverage is the book leverage of the firm, measured in year t. We also include all double and triple interaction terms of CoBAR, Distance, and Leverage. Other control variables include the lagged firm size, book-to-market ratio, lagged one-month and oneyear stock return, and the prior-year idiosyncratic volatility. Time-fixed effects are included in Columns 3 and 4. Note that since CoBAR is a time-series variable, it is subsumed by the time dummies in those regressions.

In all four regressions, stocks with higher Distance have a lower BetaChange, consistent with mean reversion. Our main focus is on the triple interaction among CoBAR, Distance, and Leverage. This mean reversion effect is significantly dampened when $\operatorname{CoBAR}$ and Leverage are high. Taken together, these results are consistent with beta-arbitrage activity causing the cross-sectional spread in betas to expand.

As a natural extension, our positive feedback channel suggests that booms and busts of beta arbitrage should be especially strong among more highly levered stocks. Figure 4 reports results where the sample is split based on leverage. Specifically, at the beginning of the holding period, we sort stocks into four equal groups using book leverage. For each leverage quartile, we compute the CoBAR return spread - i.e., the difference in four-factor alpha to the beta arbitrage strategy between high and low CoBAR periods. Reported in the figure is the cumulative difference in the CoBAR return spread between the highest and lowest leverage quartiles over the five years after portfolio formation. 
As can be seen from the figure, the difference in the CoBAR return spread rises substantially in the first twelve months, by nearly $23 \%(1.89 \% * 12, t$-statistic $=3.29)$. It then mostly reverses in the subsequent years. For example, the cumulative CoBAR return spread in years $3-5$ is $-19.8 \%(t$-statistic $=-2.19)$. This finding is consistent with our novel positive feedback channel facilitating excessive arbitrage trading activity that can potentially destabilize prices.

\section{V.B. Low Limits to Arbitrage}

We interpret our findings as consistent with arbitrage activity facilitating the correction of the slope of the security market line in the short run. However, in periods of crowded trading, arbitrageurs can cause price overshooting. In Table IX, we exploit crosssectional heterogeneity to provide additional support for our interpretation. All else equal, arbitrageurs prefer to trade stocks with low idiosyncratic volatility (to reduce tracking error), high liquidity (to facilitate opening/closing of the position), and large capitalization (to increase strategy capacity). As a consequence, we split our sample along each of these dimensions. In particular, we rank stocks into quartiles based on the variable in question (as of the beginning of the holding period); we label the quartile with the weakest limits to arbitrage as "Low LTA" and the quartile with the strongest limits to arbitrage as "High LTA." Our focus is on the long-run reversal associated with periods of high CoBAR.

The first two columns report results based on market capitalization, the third and fourth based on idiosyncratic volatility, and the final two based on liquidity. The first column of each pair shows the difference in four-factor alpha to the beta arbitrage 
strategy between high $\operatorname{CoBAR}$ periods and low $\operatorname{CoBAR}$ periods in months 1-6 while the second column shows the difference occurring in year 3 .

CoBAR is an economically stronger predictor of abnormal returns to betaarbitrage strategies in months 1-6 for large stocks, stocks with low idiosyncratic volatility, and those with high liquidity. For each of the three proxies for low limits to arbitrage, we also find economically and statistically significant differences in the predictability of year 3 returns. In summary, Table IX confirms that our effect is stronger among stocks with weaker limits of arbitrage, exactly where one expects arbitrageurs to play a more important role.

\section{V.C. Conditional Attribution}

Give that beta is moving with $\operatorname{CoBAR}$, we also estimate conditional performance attribution regressions. The last rows of Table II Panel A and Table II Panel B report the results of those regressions. We find that the long-run reversal of beta-arbitrage profits remains; there sus again an economically large reversal of beta-arbitrage profits when $C O B A R$ is high. Figure 5 plots the conditional security market line in the short and long-run as a function of lagged $\operatorname{CoBAR}$. It is easy to see from the figure our result that beta expansion and destabilization go hand-in-hand.

\section{V.D. Fresh versus Stale Beta}

Though beta-arbitrage activity may cause the beta spread to vary through time, for a feedback loop to occur, beta arbitrageurs must base their strategies on fresh estimates of 
beta rather than on stale estimates. Consistent with this claim, we show that our predictability results decay as a function of beta staleness.

We repeat the previous analysis of section IV.B, but replacing our fresh beta estimates (measured over the most recent year) with progressively staler ones. In particular, we estimate betas in each of the five years prior to the formation year. As a consequence, both the resulting beta strategy and the associated CoBAR are different for each degree of beta staleness. For each of these six beta strategies, we regress the fourfactor alpha of the strategy in months one-six and year three on its corresponding CoBAR.

Figure 6 plots the resulting regression coefficients (results for months 1-6 plotted with a blue square and results for year 3 plotted with a red circle) as a function of the degree of staleness of beta. The baseline results with the most recent beta are simply the corresponding figures from Table V. We find that both the short-run and long-run predictability documented in section IV.B decays as the beta signal becomes more and more stale. Indeed, strategies using beta estimates that are five years old display no predictability. These results are consistent with the feedback loop we propose.

\section{Conclusion}

We study the response of arbitrageurs to the flatness (and in some cases downward sloping) of the security market line. Using an approach to measuring arbitrage activity first introduced by Lou and Polk (2014), we document booms and busts in beta arbitrage. Specifically, we find that when arbitrage activity is relatively low, abnormal returns on beta-arbitrage strategies take much longer to materialize, appearing only two 
to three years after putting on the trade. In sharp contrast, when arbitrage activity is relatively high, abnormal returns on beta-arbitrage strategies occur relatively quickly, within the first six months of the trade. These strong abnormal returns then revert over the next three years. Thus, our findings are consistent with arbitrageurs exacerbating this time-variation in the expected return to beta arbitrage.

We provide evidence on a novel positive feedback channel for beta-arbitrage activity. Welch (2004) shows that firms do not issue and repurchase debt and equity to counteract the mechanical effect that stock returns have on their market leverage ratio. Since the typical firm is levered and given the mechanical effects of leverage on equity beta (Modigliani and Miller 1958), buying low-beta stocks and selling high-beta stocks may cause the cross-sectional spread in betas to increase. We show that this beta expansion occurs when beta-arbitrage activity is high and particularly so when stocks typically traded by beta arbitrageurs are particularly levered. Thus, beta arbitrageurs may actually increase their bets when the profitability of the strategy has decreased. Indeed, we find that the short-run abnormal returns to high-leverage beta-arbitrage stocks more than triples before reverting in the long run.

Interestingly, the unconditional four-factor alpha of beta arbitrage over typical holding periods for our 1970-2010 sample is close to zero, much lower than the positive value one finds for earlier samples. Thus, it seems that the response to Black, Jensen, and Scholes's (1972) famous finding is right on average. However, our conditional analysis reveals rich time-series variation that is consistent with the general message of Stein (2010): Arbitrage activity faces a significant coordination problem for unanchored strategies that have positive feedback characteristics. 


\section{References}

Amihud, Yakov, 2002, Illiquidity and stock returns: Cross-section and time series effects, Journal of Financial Markets 5, 31-56.

Antoniou, Constantinos, John A. Doukas, and Avanidhar Subrahmanyam, 2013, Investor Sentiment, and Beta Pricing, UCLA working paper.

Anton, Miguel and Christopher Polk, 2014, Connected Stocks, Journal of Finance 69, 1099-1127.

Asness, Clifford, Jacques Friedman, Robert Krail, and John Liew, 2000, Style Timing: Value versus Growth, Journal of Portfolio Management 26, 50-60.

Baker, Malcolm, Brendan Bradley and Jeffrey Wurgler, 2011, Benchmarks as Limits to Arbitrage: Understanding the Low-Volatility Anomaly, Financial Analysts Journal 67, 40-54.

Baker, Malcolm, Brendan Bradley, and Ryan Taliaferro. 2013, The Low Risk Anomaly: A Decomposition into Micro and Macro Effects, Harvard Business School working paper.

Baker, Malcolm, and Jeffrey Wurgler, 2006, Investor Sentiment and the Cross-section of Stock Returns, Journal of Finance 61, 1645

Baker, Malcolm, and Jeffry Wurgler, 2007, Investor sentiment in the stock market, Journal of Economic Perspectives 21, 129-152.

Bali, Turan, Nusret Cakici, and Robert Whitelaw, 2011, Maxing Out: Stocks as Lotteries and the Cross-Section of Expected Returns, Journal of Financial Economics $99,427-446$.

Barberis, Nicholas and Ming Huang, Stocks as Lotteries: The Implications of Probability Weighting for Security Prices, American Economic Review 98, 2066-2100.

Barberis, Nicholas and Andrei Shleifer, 2003, Style investing, Journal of Financial Economics 68, 161-199.

Barberis, Nicholas, Andrei Shleifer, and Jeffrey Wurgler, 2005, Comovement, Journal of Financial Economics 75, 283-317.

Black, Fischer. 1972, Capital Market Equilibrium with Restricted Borrowing, Journal of Business. 45, 444-454.

Black, Fischer, Michael C. Jensen and Myron Scholes. 1972. "The Capital Asset Pricing Model: Some Empirical Tests," in Studies in the Theory of Capital Markets. Michael C. Jensen, ed. New York: Praeger, pp. 79-121. 
Blitz, David, and P. V. Vliet, 2007, The Volatility Effect: Lower Risk Without Lower Return, Journal of Portfolio Management 34, 102-113.

Blitz, David, J. Pang, P. V. Vliet, 2012, The Volatility Effect in Emerging Markets, Robeco Asset Management working paper.

Buffa, Andrea, Dimitri Vayanos, and Paul Woolley, 2014, Asset Management Contracts and Equilibrium Prices, London School of Economics working paper.

Campbell, John, Stefano Giglio, Christopher Polk, and Robert Turley, 2015, An Intertemporal CAPM with Stochastic Volatility, London School of Economics working paper.

Cao, Charles, Yong Chen, Bing Liang, and Andrew Lo, Can Hedge Funds Time Market Liquidity, 2013, Journal of Financial Economics 109, 493-516.

Carhart, Mark, 1997, On Persistence in Mutual Fund Performance, Journal of Finance $52,56-82$.

Cohen, Randolph B., Christopher Polk, and Tuomo Vuolteenaho, 2005, The Value Spread, Journal of Finance 58, 609-641.

Cohen, Randolph B., Christopher Polk, and Tuomo Vuolteenaho, 2005, Money Illusion in the Stock Market: The Modigliani-Cohn Hypothesis, Quarterly Journal of Economics, $70,639-668$.

Daniel, Kent, Mark Grinblatt, Sheridan Titman, and Russ Wermers, 1997, Measuring Mutual Fund Performance with Characteristic Based Benchmarks, Journal of Finance $52,1035-1058$.

DeLong, J. Bradford, Andrei Shleifer, Lawrence H. Summers, and Robert Waldmann, 1990, Positive Feedback Investment Strategies and Destabilizing Rational Speculation, Journal of Finance 45, 379-395.

Fama, Eugene F., 1970, Efficient Capital Markets: A Review of Theory and Empirical Work, Journal of Finance 25, 383-417.

Fama, Eugene F. and Kenneth R. French, 1992, The Cross-Section of Expected Stock Returns, Journal of Finance, 47, 427-465.

Fama, Eugene F. and Kenneth R. French, 1993, Common Risk Factors in the Returns on Stocks and Bonds, Journal of Financial Economics 33, 3-56.

Fama, Eugene F. and Kenneth R. French, 1996, The CAPM is Wanted, Dead or Alive, Journal of Finance 51, 1947-1958. 
Fama, E. F., and K. R. French. 2015a. A five-factor asset pricing model, Journal of Financial Economics 116: 1-22.

Fama, E. F., and K. R. French. 2015b. Dissecting anomalies with a five-factor model, Review of Financial Studies, forthcoming.

Frazzini, Andrea and Lasse H. Pedersen, 2014, Betting Against Beta, Journal of Financial Economics 111, 1-25.

Greenwood, Robin and David Thesmar, 2011, Stock Price Fragility, Journal of Financial Economics 102, 471-490.

Hong, Harrison and David Sraer, 2014, Speculative Betas, Princeton University working paper.

J.P. Morgan, 2014, ADR Arbitrage and Program Balances, DR Advisor Insights.

Kumar, Alok, 2009, Who gambles in the stock market?, Journal of Finance 64, 18891933.

Lintner, John, 1965, The Valuation of Risky Assets and the Selection of Risky Investments in Stock Portfolios and Capital Budgets, Review of Economics and Statistics 47, 13-37.

Lou, Dong, 2012, A Flow-Based Explanation for Return Predictability, Review of Financial Studies 25, 3457-3489.

Lou, Dong, and Christopher Polk, 2014, Comomentum: Inferring Arbitrage Activity from Return Correlations, London School of Economics working paper.

Mehrling, Perry, 2005, Fischer Black and The Revolutionary Idea of Finance. Hoboken, NJ: John Wiley and Sons.

Miller, Edward M., 1977, Risk, Uncertainty, and Divergence of Opinion, Journal of Finance 32, 1151-1168.

Modigliani, Franco, and Merton H. Miller, 1958, The cost of capital, corporation finance, and the theory of investment, American Economic Review 48, 655-669.

Modigliani, Franco, and Richard Cohn, 1979, Inflation, Rational Valuation, and the Market, Financial Analysts Journal 35, 24-44.

Pástor, Luboš and Robert Stambaugh, 2003, Liquidity risk and expected stock returns, Journal of Political Economy 111, 642-685.

Pollet, Joshua and Mungo Wilson, 2010, Average Correlation and Stock Market Returns, Journal of Financial Economics 96, 364-380. 
Polk, Christopher, Sam Thompson, and Tuomo Vuolteenaho, 2006, Cross-sectional forecasts of the equity premium, Journal of Financial Economics 81, 101-141.

Rösch, Dominik, 2014, The impact of arbitrage on market liquidity, Erasmus University working paper.

Sharpe, William, 1964, Capital Asset Prices: A Theory of Market Equilibrium under Conditions of Risk, Journal of Finance 19, 425-442.

Shleifer, Andrei and Robert W. Vishny, 1997, The Limits of Arbitrage, Journal of Finance 52, 35-55.

Stein, Jeremy, 2009, Sophisticated Investors and Market Efficiency, Journal of Finance $64,1517-1548$.

Welch, Ivo, 2004, Capital Structure and Stock Returns, Journal of Political Economy 112, 106-131. 


\section{Table I: Summary Statistics}

This table provides characteristics of "CoBAR," the excess comovement among low beta stocks over the period 1970 to 2010. At the end of each month, all stocks are sorted into deciles based on their market beta calculated using daily returns in the past 12 months. To account for illiquidity and non-synchronous trading, we include on the right hand side of the regression equation five lags of the excess market return, in addition to the contemporaneous excess market return. The pre-ranking beta is simply the sum of the six coefficients from the OLS regression. Pairwise partial return correlations (controlling for the Fama-French three factors) for all stocks in the bottom beta decile are computed based on weekly stock returns in the previous 12 months. CoBAR is the average pair-wise correlation between any two stocks in the low-beta decile in year $t$. Inflation is the exponential moving average CPI growth rate over the past 100 months (where the weight on month $\mathrm{N}$ is given by $2 /(\mathrm{n}+1)$ ), as constructed by Cohen, Polk, and Vuolteenaho (2005). Sentiment is the sentiment index proposed by Wurgler and Baker (2006, 2007). Disagreement is the beta-weighted standard deviation of analysts' long-term growth rate forecasts, as used in Hong and Sraer (2012). Ted Spread is the difference between the LIBOR rate and the US Treasury bill rate. Panel A reports the summary statistics of these variables. Panel B shows the time-series correlations among these key variables for the entire sample period.

\begin{tabular}{lccccc}
\hline \multicolumn{5}{c}{ Panel A: Summary Statistics } \\
\hline Variable & $\mathrm{N}$ & Mean & Std. Dev. & Min & Max \\
CoBAR & 492 & 0.106 & 0.027 & 0.034 & 0.202 \\
Inflation & 492 & 0.004 & 0.002 & 0.002 & 0.007 \\
Sentiment & 492 & 0.007 & 0.937 & -2.578 & 2.691 \\
Disagreement & 348 & 4.423 & 0.897 & 3.266 & 7.338 \\
Ted Spread & 312 & 0.567 & 0.412 & 0.127 & 3.443 \\
\hline
\end{tabular}

\begin{tabular}{lccccc}
\hline \multicolumn{5}{c}{ Panel B: Correlation } \\
\hline CoBAR & Inflation & Sentiment & Disagreemt & Ted Spread \\
Inflation & 1.000 & & & & \\
Sentiment & -0.336 & 1.000 & & & \\
Disagreement & -0.047 & 0.034 & 1.000 & & \\
Ted Spread & 0.339 & -0.382 & 0.390 & 1.000 & \\
\hline
\end{tabular}




\section{Table II: Determinants of CoBAR}

This table reports regressions of CoBAR, described in Table I, on lagged variables plausibly linked to arbitrage activity. At the end of each month, all stocks are sorted into deciles based on their market beta calculated using daily returns in the past 12 months. To account for illiquidity and non-synchronous trading, we include on the right hand side of the regression equation five lags of the excess market return, in addition to the contemporaneous excess market return. The pre-ranking beta is simply the sum of the six coefficients from the OLS regression. The dependent variable in the regressions, CoBAR, is the average pairwise partial weekly return correlation in the low-beta decile over 12 months. Inst Own is the aggregate institutional ownership of the low-beta decile, $A U M$ is the logarithm of the total assets under management of long-short equity hedge funds. Inflation is the exponential moving average CPI growth rate over the past 100 months (where the weight on month $\mathrm{N}$ is given by $2 /(\mathrm{n}+1)$ ), as constructed by Cohen, Polk, and Vuolteenaho (2005). Sentiment is the sentiment index proposed by Wurgler and Baker (2006, 2007). Disagreement is the beta-weighted standard deviation of analysts' long-term growth rate forecasts, as used in Hong and Sraer (2012). Ted Spread is the difference between the LIBOR rate and the US Treasury bill rate. We also include in the regression the Pastor-Stambaugh liquidity factor (PS Liquidity). A trend dummy is included in all regression specifications. All independent variables are divided by their corresponding standard deviation, so that the coefficient represents the effect of a one-standard-deviation change in the independent variable on $\operatorname{CoBAR}$. Standard errors are shown in brackets. ${ }^{*},{ }^{*},{ }^{* * *}$ denote significance at the $10 \%, 5 \%$, and $1 \%$ level, respectively.

\begin{tabular}{|c|c|c|c|c|}
\hline \multirow[t]{2}{*}{ DepVar } & \multicolumn{4}{|c|}{$\operatorname{CoBAR}_{t}$} \\
\hline & {$[1]$} & {$[2]$} & {$[3]$} & {$[4]$} \\
\hline \multirow[t]{2}{*}{ Inst Own $n_{t-1}$} & $0.018^{* * *}$ & $0.025^{* * *}$ & $0.014^{* * *}$ & $0.012^{* *}$ \\
\hline & {$[0.007]$} & {$[0.006]$} & {$[0.005]$} & {$[0.006]$} \\
\hline \multirow[t]{2}{*}{$A U M_{t-1}$} & & $0.008^{* * *}$ & & $0.005^{* *}$ \\
\hline & & {$[0.002]$} & & {$[0.002]$} \\
\hline \multirow[t]{2}{*}{ Inflation $_{t}$} & & & $-0.016^{*}$ & -0.005 \\
\hline & & & {$[0.009]$} & {$[0.004]$} \\
\hline \multirow[t]{2}{*}{ Sentiment $_{t}$} & & & 0.003 & 0.004 \\
\hline & & & {$[0.008]$} & {$[0.021]$} \\
\hline \multirow[t]{2}{*}{ Disagreement $_{t}$} & & & 0.007 & 0.006 \\
\hline & & & {$[0.005]$} & {$[0.013]$} \\
\hline \multirow[t]{2}{*}{ Ted Spread $_{t}$} & & & $0.010^{* * *}$ & $0.011^{* *}$ \\
\hline & & & {$[0.003]$} & {$[0.005]$} \\
\hline \multirow[t]{2}{*}{ PS Liquidity $_{t}$} & $0.007^{* *}$ & $0.008^{* * *}$ & $0.010^{* * *}$ & $0.010^{* * *}$ \\
\hline & {$[0.003]$} & {$[0.003]$} & {$[0.002]$} & {$[0.003]$} \\
\hline TREND & YES & YES & YES & YES \\
\hline $\operatorname{Adj}-R^{2}$ & 0.152 & 0.382 & 0.372 & 0.441 \\
\hline No. Obs. & 357 & 180 & 357 & 180 \\
\hline
\end{tabular}




\section{Table III: Forecasting Beta-arbitrage Returns with CoBAR}

This table reports returns to the beta arbitrage strategy as a function of lagged CoBAR. At the end of each month, all stocks are sorted into deciles based on their market beta calculated using daily returns in the past 12 months. To account for illiquidity and non-synchronous trading, we include on the right hand side of the regression equation five lags of the excess market return, in addition to the contemporaneous excess market return. The pre-ranking beta is simply the sum of the six coefficients from the OLS regression. All months are then classified into five groups based on $\operatorname{CoBAR}$, the average pairwise partial weekly return correlation in the low-beta decile over the past 12 months. Reported below are the returns to the beta arbitrage strategy (i.e., to go long the value-weight low-beta decile and short the value-weighted high-beta decile) in each of the three years after portfolio formation during 1970 to 2010, following low to high CoBAR. Panels A and B report, respectively, the average monthly three-factor alpha and Carhart fourfactor alpha of the beta arbitrage strategy. "5-1" is the difference in monthly returns to the long-short strategy following high vs. low CoBAR; "5-1 Conditional" is the difference in conditional abnormal returns (i.e., allowing for risk loadings to vary as a function of CoBAR) following high vs. low CoBAR. T-statistics, shown in parentheses, are computed based on standard errors corrected for serial-dependence with 12 lags. $5 \%$ statistical significance is indicated in bold.

\begin{tabular}{|c|c|c|c|c|c|c|c|c|c|}
\hline \multicolumn{10}{|c|}{ Panel A: Fama-French-Adjusted Beta-arbitrage Returns } \\
\hline & & \multicolumn{2}{|c|}{ Months 1-6 } & \multicolumn{2}{|c|}{ Year 1} & \multicolumn{2}{|c|}{ Year 2} & \multicolumn{2}{|c|}{ Year 3} \\
\hline Rank & No Obs. & Estimate & t-stat & Estimate & t-stat & Estimate & t-stat & Estimate & t-stat \\
\hline 1 & 98 & $0.37 \%$ & $(1.21)$ & $0.48 \%$ & $(1.92)$ & $0.61 \%$ & $(2.05)$ & $0.85 \%$ & $(2.95)$ \\
\hline 2 & 99 & $-0.46 \%$ & $(-1.38)$ & $0.10 \%$ & $(0.39)$ & $0.69 \%$ & $(2.54)$ & $0.07 \%$ & $(0.35)$ \\
\hline 3 & 98 & $-0.41 \%$ & $(-1.23)$ & $-0.04 \%$ & $(-0.14)$ & $0.45 \%$ & $(1.64)$ & $0.43 \%$ & $(1.50)$ \\
\hline 4 & 99 & $-0.27 \%$ & $(-0.90)$ & $-0.08 \%$ & $(-0.34)$ & $-0.27 \%$ & $(-0.90)$ & $-0.10 \%$ & $(-0.24)$ \\
\hline 5 & 98 & $1.56 \%$ & $(3.09)$ & $0.92 \%$ & $(2.12)$ & $-0.08 \%$ & $(-0.15)$ & $-0.74 \%$ & $(-2.15)$ \\
\hline $5-1$ & & $1.19 \%$ & $(2.14)$ & $0.44 \%$ & $(0.92)$ & $-0.69 \%$ & $(-1.13)$ & $-1.60 \%$ & $(-3.29)$ \\
\hline \multicolumn{2}{|c|}{$5-1$ (Conditional) } & $0.77 \%$ & $(1.89)$ & $0.05 \%$ & $(0.13)$ & $-0.93 \%$ & $(-1.56)$ & $-1.44 \%$ & $(-3.19)$ \\
\hline \multicolumn{10}{|c|}{ Panel B: Four-Factor Adjusted Beta-arbitrage Returns } \\
\hline & & \multicolumn{2}{|c|}{ Months 1-6 } & \multicolumn{2}{|c|}{ Year 1} & \multicolumn{2}{|c|}{ Year 2} & \multicolumn{2}{|c|}{ Year 3} \\
\hline Rank & No Obs. & Estimate & t-stat & Estimate & t-stat & Estimate & t-stat & Estimate & t-stat \\
\hline 1 & 98 & $0.02 \%$ & $(0.08)$ & $0.16 \%$ & $(0.61)$ & $0.38 \%$ & $(1.23)$ & $0.54 \%$ & $(2.03)$ \\
\hline 2 & 99 & $-0.61 \%$ & $(-1.88)$ & $-0.18 \%$ & $(-0.72)$ & $0.39 \%$ & $(1.40)$ & $-0.12 \%$ & $(-0.48)$ \\
\hline 3 & 98 & $-0.60 \%$ & $(-1.84)$ & $-0.30 \%$ & $(-0.98)$ & $0.15 \%$ & $(0.51)$ & $0.22 \%$ & $(0.84)$ \\
\hline 4 & 99 & $-0.56 \%$ & $(-1.80)$ & $-0.41 \%$ & $(-1.67)$ & $-0.60 \%$ & $(-1.92)$ & $-0.45 \%$ & $(-1.03)$ \\
\hline 5 & 98 & $1.19 \%$ & $(2.34)$ & $0.64 \%$ & $(1.50)$ & $-0.22 \%$ & $(-0.47)$ & $-1.04 \%$ & $(-3.12)$ \\
\hline $5-1$ & & $1.16 \%$ & $(2.08)$ & $0.49 \%$ & $(1.03)$ & $-0.61 \%$ & $(-1.07)$ & $-1.58 \%$ & $(-3.33)$ \\
\hline $5-1(\mathrm{C}$ & nal) & $0.56 \%$ & $(1.21)$ & $0.18 \%$ & $(0.48)$ & $-1.12 \%$ & $(-2.22)$ & $-1.72 \%$ & $(-4.06)$ \\
\hline
\end{tabular}




\section{Table IV: Robustness Checks}

This table reports returns to the beta arbitrage strategy as a function of lagged CoBAR. At the end of each month, all stocks are sorted into deciles based on their market beta calculated using daily returns in the past 12 months. To account for illiquidity and non-synchronous trading, we include on the right hand side of the regression equation five lags of the excess market return, in addition to the contemporaneous excess market return. The pre-ranking beta is simply the sum of the six coefficients from the OLS regression. All months are then classified into five groups based on $C o B A R$, the average pairwise partial weekly return correlation in the low-beta decile over the past 12 months. Reported below is the difference in four-factor alpha to the beta arbitrage strategy between high CoBAR periods and low CoBAR periods. Year zero is the beta portfolio ranking period. Row 1 shows the baseline results which are also reported in Table III. Row 2 shows the same analysis for the earlier sample (1927-1969) as a placebo test. In rows 3 and 4 , we exclude the tech bubble crash and the recent financial crisis from our sample. In rows 5-8, we rank all months based on the inflation index (Cohen, Polk, and Vuolteenaho, 2005), sentiment index (Wurgler and Baker, 2006), aggregate analyst forecast dispersion (Hong and Sraer, 2014), and Ted Spread (Frazzini and Pedersen, 2014), respectively. In row 9, we also control for the UMD factor in computing CoBAR. In row 10 , we control for both large- and small-cap HML in computing CoBAR. In row 11, we control for the FamaFrench five factor model that adds profitability and investment to their three-factor model. In row 12 , we perform the entire analysis on an industry-adjusted basis by sorting stocks into beta deciles within industries. In row 13, we instead measure the correlation between the high and low-beta portfolios, with a low correlation indicating high arbitrage activity. In Rows 14 and 15, we examine upside and downside CoBAR, as distinguished by the median low-beta portfolio return. In Rows 16-21, we replace CoBAR with residual $C o B A R$ from a time-series regression where we purge from CoBAR variation linked to, respectively, CoMomentum and CoValue (Lou and Polk, 2014), the average pair-wise correlation in the market, the lagged 36-month volatility of the BAB factor (Frazzini and Pedersen, 2013), market volatility over the past 12 months, and a trend. T-statistics, shown in parentheses, are computed based on standard errors corrected for serial-dependence with 12 lags. $5 \%$ statistical significance is indicated in bold. 


\begin{tabular}{|c|c|c|c|c|}
\hline \multicolumn{5}{|c|}{ Four-Factor Adjusted Beta-arbitrage Returns } \\
\hline & \multicolumn{2}{|c|}{ Months 1-6 } & \multicolumn{2}{|c|}{ Year 3} \\
\hline & Estimate & t-stat & Estimate & t-stat \\
\hline \multicolumn{5}{|l|}{ Subsamples } \\
\hline Full Sample: 1970-2010 & $1.16 \%$ & $(2.08)$ & $-1.58 \%$ & $(-3.33)$ \\
\hline Early sample (Placebo test): 1927-1969 & $0.68 \%$ & $(1.37)$ & $0.31 \%$ & $(0.71)$ \\
\hline Excluding 2001 & $1.01 \%$ & $(1.99)$ & $-1.57 \%$ & $(-3.41)$ \\
\hline Excluding 2007-2009 & $1.09 \%$ & $(2.00)$ & $-1.61 \%$ & $(-3.25)$ \\
\hline \multicolumn{5}{|l|}{ Other predictors of beta-arbitrage returns } \\
\hline Inflation & $0.45 \%$ & $(0.98)$ & $0.10 \%$ & $(0.24)$ \\
\hline Sentiment & $1.39 \%$ & $(2.99)$ & $0.47 \%$ & $(0.83)$ \\
\hline Disagreement & $0.63 \%$ & $(1.04)$ & $0.59 \%$ & $(1.26)$ \\
\hline Ted Spread & $-0.54 \%$ & $(-0.79)$ & $-0.63 \%$ & $(-1.44)$ \\
\hline \multicolumn{5}{|l|}{ Alternative definitions of $C O B A R$} \\
\hline Controlling for UMD & $0.89 \%$ & $(1.78)$ & $-1.63 \%$ & $(-3.55)$ \\
\hline Controlling for Large/Small-Cap HML & $1.55 \%$ & $(2.55)$ & $-1.68 \%$ & $(-3.45)$ \\
\hline Controlling for FF Five Factors & $0.85 \%$ & $(1.72)$ & $-1.28 \%$ & $(-2.61)$ \\
\hline Controlling for Industry Factors & $0.93 \%$ & $(1.69)$ & $-1.32 \%$ & $(-2.95)$ \\
\hline Correl btw High and Low Beta Stocks & $0.31 \%$ & $(1.02)$ & $-0.91 \%$ & $(-2.09)$ \\
\hline Upside $C o B A R$ & $1.08 \%$ & $(2.06)$ & $-0.99 \%$ & $(-2.20)$ \\
\hline Downside $C o B A R$ & $0.18 \%$ & $(0.30)$ & $-0.41 \%$ & $(-0.87)$ \\
\hline \multicolumn{5}{|l|}{$\underline{\text { Residual CoBAR }}$} \\
\hline Controlling for CoMomentum & $1.09 \%$ & $(1.98)$ & $-1.57 \%$ & $(-3.27)$ \\
\hline Controlling for CoValue & $1.10 \%$ & $(1.97)$ & $-1.60 \%$ & $(-3.39)$ \\
\hline Controlling for MKT CORR & $0.94 \%$ & $(1.94)$ & $-1.78 \%$ & $(-4.21)$ \\
\hline Controlling for $\mathrm{Vol}(\mathrm{BAB})$ & $1.13 \%$ & $(2.29)$ & $-1.43 \%$ & $(-3.03)$ \\
\hline Controlling for Mktvol12 & $1.50 \%$ & $(2.44)$ & $-1.69 \%$ & $(-3.50)$ \\
\hline Controlling for Trend & $1.13 \%$ & $(2.12)$ & $-1.65 \%$ & $(-3.54)$ \\
\hline
\end{tabular}




\section{Table V: Regression Analysis}

This table reports returns to the beta arbitrage strategy as a function of lagged CoBAR. At the end of each month, all stocks are sorted into deciles based on their market beta calculated using daily returns in the past 12 months. To account for illiquidity and non-synchronous trading, we include on the right hand side of the regression equation five lags of the excess market return, in addition to the contemporaneous excess market return. The pre-ranking beta is simply the sum of the six coefficients from the OLS regression. The dependent variable is the four-factor alpha of the beta arbitrage strategy (i.e., a portfolio that is long the value-weight low-beta decile and short the value-weighted high-beta decile). The main independent variable is $C o B A R$, the average pairwise partial weekly three-factor residual correlation within the low-beta decile over the past 12 months. We also include in the regression the inflation index (Cohen, Polk, and Vuolteenaho, 2005), sentiment index (Wurgler and Baker, 2006), aggregate analyst forecast dispersion (Hong and Sraer, 2012), Ted Spread - the difference between the LIBOR rate and the US Treasury bill rate, the ValueSpread - the spread in log book-to-market-ratios across the low-beta and high-beta deciles, and the market volatility over the past 12 months. The first three columns examine returns to the beta arbitrage strategy in months 1-6, and the next three columns examine the returns in year 3 after portfolio formation. We report results based on Carhart four-factor adjustments. T-statistics, shown in brackets, are computed based on standard errors corrected for serial-dependence with 12 lags. *, **, *** denote significance at the $10 \%, 5 \%$, and $1 \%$ level, respectively.

\begin{tabular}{|c|c|c|c|c|c|c|}
\hline \multirow[t]{3}{*}{ DepVar } & \multicolumn{6}{|c|}{ Four-Factor Alpha to the Beta Arbitrage Strategy } \\
\hline & \multicolumn{3}{|c|}{ Months 1-6 } & \multicolumn{3}{|c|}{ Year 3} \\
\hline & {$[1]$} & {$[2]$} & {$[3]$} & {$[4]$} & {$[5]$} & {$[6]$} \\
\hline \multirow[t]{2}{*}{ CoBAR } & $0.189^{* * *}$ & $0.211^{* * *}$ & $0.201^{*}$ & $-0.188^{* * *}$ & $-0.166^{* * *}$ & $-0.178^{* * *}$ \\
\hline & {$[0.069]$} & {$[0.075]$} & {$[0.118]$} & {$[0.054]$} & {$[0.050]$} & {$[0.065]$} \\
\hline \multirow[t]{2}{*}{ Inflation } & & 0.001 & 0.004 & & 0.000 & -0.003 \\
\hline & & {$[0.002]$} & {$[0.004]$} & & {$[0.001]$} & {$[0.003]$} \\
\hline \multirow[t]{2}{*}{ Sentiment } & & $0.005^{* * *}$ & $0.005^{* *}$ & & 0.002 & -0.001 \\
\hline & & {$[0.002]$} & {$[0.002]$} & & {$[0.002]$} & {$[0.002]$} \\
\hline \multirow[t]{2}{*}{ Disagreement } & & & 0.002 & & & 0.003 \\
\hline & & & {$[0.003]$} & & & {$[0.003]$} \\
\hline \multirow[t]{2}{*}{ Ted Spread } & & & $-0.005^{*}$ & & & 0.002 \\
\hline & & & {$[0.003]$} & & & {$[0.002]$} \\
\hline \multirow[t]{2}{*}{ ValueSpread } & & 0.000 & 0.001 & & -0.005 & -0.005 \\
\hline & & {$[0.003$} & {$[0.004]$} & & {$[0.003]$} & {$[0.003]$} \\
\hline \multirow[t]{2}{*}{ Mktvol12 } & & -0.035 & -0.045 & & 0.006 & -0.077 \\
\hline & & {$[0.099$} & {$[0.138]$} & & {$[0.008]$} & {$[0.085]$} \\
\hline Adj-R $R^{2}$ & 0.046 & 0.092 & 0.146 & 0.090 & 0.132 & 0.191 \\
\hline No. Obs. & 492 & 492 & 312 & 492 & 492 & 312 \\
\hline
\end{tabular}




\section{Table VI: Predicting the Security Market Line}

This table reports regressions of the intercept and slope of the security market line on lagged CoBAR. At the end of each month, all stocks are sorted into vigintiles based on their market beta calculated using daily returns in the past 12 months. To account for illiquidity and non-synchronous trading, we include on the right hand side of the regression equation five lags of the excess market return, in addition to the contemporaneous excess market return. The pre-ranking beta is simply the sum of the six coefficients from the OLS regression. We then estimate two security market lines based on these 20 portfolios formed in each period: one SML using monthly portfolio returns in months 1-6, and the other using monthly portfolio returns in year 3 after portfolio formation. The post-ranking betas are calculated by regressing each of the 20 portfolios' value-weighted monthly returns on the corresponding market return. Following Fama and French (1992), we use the entire sample to compute post-ranking betas. The dependent variable in Panel A is the intercept of the SML, while that in Panel B is the slope of the SML. The main independent variable is $C o B A R$, the average pairwise partial weekly three-factor residual correlation within the low-beta decile over the past 12 months. We also include in the regressions the inflation index, sentiment index, aggregate analyst forecast dispersion, and Ted Spread. Other (unreported) control variables include the contemporaneous market excess return, SMB return, and HML return. Standard errors, shown in brackets, are computed based on standard errors corrected for serial-dependence with 6 or 12 lags, as appropriate. *, $* *, * * *$ denote significance at the $10 \%, 5 \%$, and $1 \%$ level, respectively.

\begin{tabular}{|c|c|c|c|c|c|c|}
\hline \multicolumn{7}{|c|}{ Panel A: DepVar = Intercept of SML } \\
\hline & & Months 1-( & & & Year3 & \\
\hline \multirow[t]{2}{*}{ CoBAR } & $0.184^{* *}$ & $0.207 * * *$ & $0.158^{* *}$ & $-0.217^{* * *}$ & $-0.174 * * *$ & $-0.186^{* * *}$ \\
\hline & {$[0.091]$} & {$[0.057]$} & {$[0.080]$} & {$[0.058]$} & {$[0.057]$} & {$[0.062]$} \\
\hline \multirow[t]{2}{*}{ Inflation } & & 0.001 & 0.001 & & 0.000 & -0.004 \\
\hline & & {$[0.001]$} & {$[0.002]$} & & {$[0.002]$} & {$[0.003]$} \\
\hline \multirow[t]{2}{*}{ Sentiment } & & $0.005^{* * *}$ & $0.005^{* *}$ & & 0.002 & -0.001 \\
\hline & & {$[0.001]$} & {$[0.002]$} & & {$[0.002]$} & {$[0.002]$} \\
\hline \multirow[t]{2}{*}{ Disagreement } & & & 0.000 & & & 0.000 \\
\hline & & & {$[0.002]$} & & & {$[0.003]$} \\
\hline \multirow[t]{2}{*}{ Ted Spread } & & & $-0.003^{*}$ & & & 0.003 \\
\hline & & & {$[0.002]$} & & & {$[0.002]$} \\
\hline Adj- $R^{2}$ & 0.051 & 0.402 & 0.492 & 0.087 & 0.338 & 0.542 \\
\hline \multirow[t]{3}{*}{ No. Obs. } & 492 & 492 & 312 & 492 & 492 & 312 \\
\hline & \multicolumn{5}{|c|}{ Panel B: Dep Var = Slope of SML } & \\
\hline & & Months 1- & & & Year3 & \\
\hline \multirow[t]{2}{*}{ CoBAR } & $-0.355^{* * *}$ & $-0.197 * * *$ & $-0.150^{*}$ & $0.238^{* * *}$ & $0.194^{* * *}$ & $0.180^{* * *}$ \\
\hline & {$[0.110]$} & {$[0.058]$} & {$[0.085]$} & {$[0.074]$} & {$[0.055]$} & {$[0.065]$} \\
\hline \multirow[t]{2}{*}{ Inflation } & & -0.001 & -0.002 & & 0.000 & 0.003 \\
\hline & & {$[0.001]$} & {$[0.003]$} & & {$[0.002]$} & {$[0.003]$} \\
\hline \multirow[t]{2}{*}{ Sentiment } & & $-0.005^{* * *}$ & $-0.006^{* * *}$ & & -0.002 & 0.001 \\
\hline & & {$[0.001]$} & {$[0.002]$} & & {$[0.002]$} & {$[0.002]$} \\
\hline \multirow[t]{2}{*}{ Disagreement } & & & 0.000 & & & 0.000 \\
\hline & & & {$[0.003]$} & & & {$[0.003]$} \\
\hline \multirow[t]{2}{*}{ Ted Spread } & & & $0.004^{*}$ & & & -0.003 \\
\hline & & & {$[0.002]$} & & & {$[0.002]$} \\
\hline $\operatorname{Adj}-R^{2}$ & 0.104 & 0.680 & 0.715 & 0.075 & 0.545 & 0.698 \\
\hline No. Obs. & 492 & 492 & 312 & 492 & 492 & 312 \\
\hline
\end{tabular}




\section{Table VII: Beta Expansion, Time-Series Analysis}

This table examines time-series beta expansion associated with arbitrage trading. Panel A reports the baseline regression. The dependent variable in columns 1 and 2 is the beta spread between the high-beta and low-beta deciles (ranked in year $t$ ) in year $t+1$. The dependent variable in columns 3 and 4 is the fraction of stocks in the bottom beta decile ranked in year $t$ that remain in the bottom beta decile in year $t+1$ (the two periods are non-overlapping). CoBAR is the average pairwise partial weekly three-factor residual correlation within the low-beta decile over the past 12 months. Leverage is a quintile dummy based on the average value-weighted book leverage of the bottom and top beta deciles. We also include in the regression an interaction term between $C o B A R$ and Leverage. Panel B reports a battery of robustness checks. The dependent variable in all rows is the beta spread between the high-beta and low-beta deciles in year $t+1$. Reported below is the coefficient on the interaction of CoBAR and Leverage. Row 1 shows the baseline results which are also reported in Table III. In Rows 2 and 3, we exclude the tech bubble crash and the recent financial crisis from our sample. In Row 4, we also control for the UMD factor in computing CoBAR. In Row 5, we control for both large- and small-cap HML in computing CoBAR. In Row 6, we control for the Fama-French five factor model that adds profitability and investment to their three-factor model. In Row 7, we perform the entire analysis on an industry-adjusted basis by sorting stocks into beta deciles within industries. In Row 8, we instead measure the correlation between the high and low-beta portfolios, with a low correlation indicating high arbitrage activity. In Rows 9 and 10, we examine upside and downside CoBAR, as distinguished by the median low-beta portfolio return. In Rows 11-16, we replace CoBAR with residual CoBAR from a time-series regression where we purge from CoBAR variation linked to, respectively, CoMomentum and CoValue (Lou and Polk, 2014), the average pair-wise correlation in the market, the lagged 36-month volatility of the BAB factor (Frazzini and Pedersen, 2013), market volatility over the past 12 months, and a trend. Standard errors are shown in brackets. ${ }^{*},{ }^{* *},{ }^{* * *}$ denote significance at the $10 \%, 5 \%$, and $1 \%$ level, respectively.

\begin{tabular}{lcccc}
\hline \multicolumn{5}{c}{ Panel A: Baseline Regression } \\
\hline DepVar & \multicolumn{3}{c}{ BetaSpread $_{t+1}$} & Fraction $_{t+1}$ \\
\hline \multirow{3}{*}{ BetaSpread } & {$[1]$} & {$[2]$} & {$[3]$} & {$[4]$} \\
& $0.287^{* * *}$ & $0.281^{* * *}$ & & \\
CoBAR & {$[0.060]$} & {$[0.058]$} & & \\
& $1.539^{* * *}$ & 0.504 & 0.598 & -1.686 \\
Leverage & {$[0.518]$} & {$[0.636]$} & {$[1.916]$} & {$[2.078]$} \\
& & $-0.037^{* * *}$ & & $-0.253^{* * *}$ \\
CoBAR * Leverage & & {$[0.012]$} & & {$[0.043]$} \\
& & $0.423^{* * *}$ & & $0.982^{* * *}$ \\
Adj-R ${ }^{2}$ & {$[0.126]$} & & {$[0.281]$} \\
No. Obs. & 0.128 & 0.150 & -0.002 & 0.077 \\
\hline
\end{tabular}




\begin{tabular}{lll}
\hline \multicolumn{3}{c}{ Panel B: Robustness Checks } \\
\hline \multicolumn{3}{c}{ Dep Var $=$ BetaSpread $_{t+1}$} \\
\hline Subsamples & & \\
Full Sample:1970-2010 & $0.423^{* * *}$ & {$[0.126]$} \\
Excluding 2001 & $0.436^{* * *}$ & {$[0.117]$} \\
Excluding 2007-2009 & $0.242^{* *}$ & {$[0.086]$} \\
& & \\
Alternative definitions of COBAR & \\
Controlling for UMD & & \\
Controlling for Large/Small-Cap HML & $0.466^{* * *}$ & {$[0.123]$} \\
Controlling for FF Five Factors & $0.425^{* * *}$ & {$[0.123]$} \\
Controlling for Industry Factors & $0.437^{* * *}$ & {$[0.155]$} \\
Correl btw High and Low Beta Stocks & $0.516^{* * *}$ & {$[0.162]$} \\
Upside CoBAR & $0.215^{* * *}$ & {$[0.071]$} \\
Downside CoBAR & $0.601^{* * *}$ & {$[0.159]$} \\
& $0.229^{*}$ & {$[0.125]$} \\
Residual CoBAR & & \\
Controlling for CoMomentum & & \\
Controlling for CoValue & $0.323^{* *}$ & {$[0.095]$} \\
Controlling for MKT CORR & $0.413^{* * *}$ & {$[0.118]$} \\
Controlling for Vol(BAB) & $0.248^{* *}$ & {$[0.087]$} \\
Controlling for Mktvol12 & $0.394^{* * *}$ & {$[0.117]$} \\
Controlling for Trend & $0.435^{* * *}$ & {$[0.158]$} \\
\hline & $0.335^{* * *}$ & {$[0.121]$} \\
\hline
\end{tabular}




\section{Table VIII: Beta Expansion, Cross-Sectional Analysis}

This table reports panel regressions of subsequent changes in stock beta on lagged CoBAR. At the end of each month, all stocks are sorted into deciles based on their market beta calculated using daily returns in the past 12 months. To account for illiquidity and non-synchronous trading, we include on the right hand side of the regression equation five lags of the excess market return, in addition to the contemporaneous excess market return. The pre-ranking beta is simply the sum of the six coefficients from the OLS regression. The dependent variable is the change in stock beta from year $t$ to $t+1$ (non-overlapping periods). The main independent variable is lagged $\operatorname{CoBAR}$, the average pairwise excess weekly return correlation in the low-beta decile over the past 12 months. Distance is the difference between a stock's beta decile rank and the average rank of 5.5 in year $t$. Leverage is the book leverage of the firm, measured in year $t$. We also include all double and triple interaction terms of CoBAR, Distance, and Leverage. Other (unreported) control variables include lagged firm size, book-to-market ratio, momentum, idiosyncratic volatility (over the prior year), and the past one-month return. Time-fixed effects are included in Columns 3 and 4. (Since $C o B A R$ is a time-series variable, it is subsumed by the time dummies.) Standard errors, shown in brackets, are double clustered at both the firm and year-month levels. ${ }^{*},{ }^{* *}$, ${ }^{* * *}$ denote significance at the $10 \%, 5 \%$, and $1 \%$ level, respectively.

\begin{tabular}{|c|c|c|c|c|}
\hline \multirow[t]{2}{*}{ DepVar } & \multicolumn{4}{|c|}{ Beta Change $_{t+1}$} \\
\hline & {$[1]$} & {$[2]$} & {$[3]$} & {$[4]$} \\
\hline \multirow[t]{2}{*}{ CoBAR } & $0.408^{* * *}$ & $0.322^{* * *}$ & & \\
\hline & {$[0.151]$} & {$[0.153]$} & & \\
\hline \multirow[t]{2}{*}{ Distance } & $-0.077^{* * *}$ & $-0.078^{* * *}$ & $-0.077^{* * *}$ & $-0.078^{* * *}$ \\
\hline & {$[0.004]$} & {$[0.006]$} & {$[0.005]$} & {$[0.006]$} \\
\hline \multirow[t]{2}{*}{ CoBAR * Distance } & $0.078^{* *}$ & 0.038 & 0.022 & 0.001 \\
\hline & {$[0.041]$} & {$[0.048]$} & {$[0.021]$} & {$[0.048]$} \\
\hline \multirow[t]{2}{*}{ Leverage } & & $-0.007^{* * *}$ & & $-0.005^{* * *}$ \\
\hline & & {$[0.002]$} & & {$[0.002]$} \\
\hline \multirow[t]{2}{*}{ CoBAR* Leverage } & & $0.043^{* * *}$ & & $0.027^{*}$ \\
\hline & & {$[0.016]$} & & {$[0.016]$} \\
\hline \multirow[t]{2}{*}{ Leverage $*$ Distance } & & 0.000 & & 0.000 \\
\hline & & {$[0.001]$} & & {$[0.001]$} \\
\hline \multirow[t]{2}{*}{ CoBAR $*$ Leverage $*$ Distance } & & $0.017^{* * *}$ & & $0.013^{* * *}$ \\
\hline & & {$[0.005]$} & & {$[0.004]$} \\
\hline Time Fixed Effect & No & No & Yes & Yes \\
\hline Adj-R2 & 0.216 & 0.219 & 0.279 & 0.282 \\
\hline No. Obs. & $1,056,219$ & $1,056,219$ & $1,056,219$ & $1,056,219$ \\
\hline
\end{tabular}




\section{Table IX: Limits to Arbitrage}

This table reports returns to the beta arbitrage strategy as a function of lagged CoBAR in various subsamples ranked by proxies for limits to arbitrage (LTA). At the end of each month, all stocks are sorted into deciles based on their market beta calculated using daily returns in the past 12 months. To account for illiquidity and non-synchronous trading, we include on the right hand side of the regression equation five lags of the excess market return, in addition to the contemporaneous excess market return. The pre-ranking beta is simply the sum of the six coefficients from the OLS regression. All months are then classified into five groups based on $\operatorname{CoBAR}$, the average pairwise partial return correlation in the low-beta decile over the past 12 months. Reported below is the difference in four-factor alpha to the beta arbitrage strategy between high CoBAR periods and low CoBAR periods. Year zero is the beta portfolio ranking period. "Low LTA" corresponds to the subsample of stocks with low limits to arbitrage, and "high LTA" corresponds to the subsample with high limits to arbitrage. "Low-High" is the difference in monthly portfolio alpha between the two subsamples. We measure limits to arbitrage using three common proxies. In columns 1-2, we rank stocks into quartiles based on market capitalization (as of the beginning of the holding period); we label the top quartile as "Low LTA" and the bottom quartile as "High LTA." In columns 3-4, we rank stocks into quartiles based on idiosyncratic volatility with regard to the Carhart four-factor model (as of the beginning of the holding period); we label the bottom quartile as "Low LTA" and the top quartile as "High LTA." In columns 5-6, we rank stocks into quartiles based on the illiquidity measure of Amihud (2002) (as of the beginning of the holding period); we label the bottom quartile as "Low LTA" and the top quartile as "High LTA." T-statistics, shown in parentheses, are computed based on standard errors corrected for serialdependence with 12 lags. $5 \%$ statistical significance is indicated in bold.

\begin{tabular}{lcccccc}
\hline & \multicolumn{2}{c}{ Market Cap } & \multicolumn{2}{c}{ Idiosyncratic Volatility } & \multicolumn{2}{c}{ Illiquidity } \\
\hline Low LTA & Months 1-6 & Year 3 & Months 1-6 & Year 3 & Months 1-6 & Year 3 \\
& $1.29 \%$ & $-1.67 \%$ & $1.64 \%$ & $-1.67 \%$ & $1.30 \%$ & $-1.58 \%$ \\
\multirow{3}{*}{ High LTA } & $(2.43)$ & $(-3.17)$ & $(3.03)$ & $(-3.36)$ & $(2.23)$ & $(-2.94)$ \\
& $0.12 \%$ & $-0.36 \%$ & $0.90 \%$ & $-1.02 \%$ & $0.31 \%$ & $-0.47 \%$ \\
& $(0.24)$ & $(-0.59)$ & $(1.02)$ & $(-1.81)$ & $(1.32)$ & $(-0.85)$ \\
\hline Low-High & $1.17 \%$ & $-1.31 \%$ & $0.74 \%$ & $-0.65 \%$ & $1.00 \%$ & $-1.11 \%$ \\
& $(2.03)$ & $(-2.05)$ & $(-1.77)$ & $(2.05)$ & $(1.79)$ & $(-2.02)$ \\
\hline
\end{tabular}



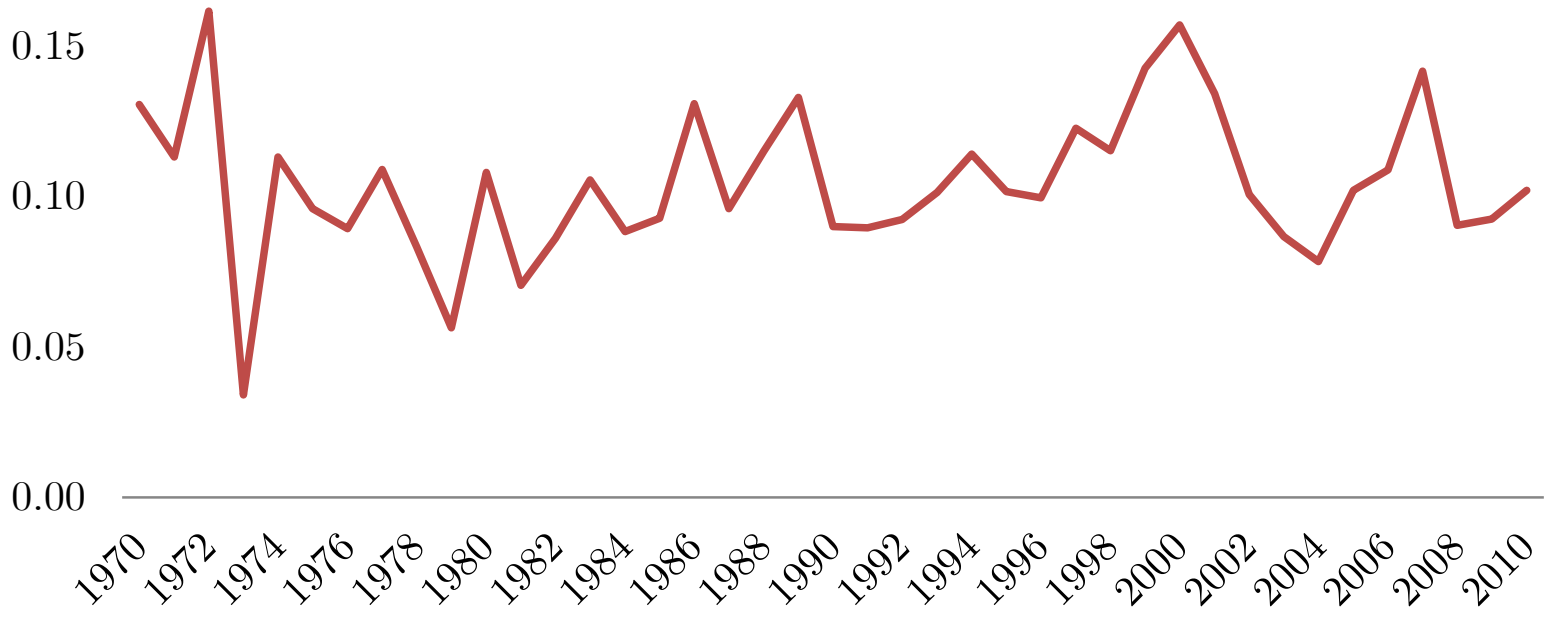

Figure 1: This figure shows the time series of the CoBAR measure. At the end of each month, all stocks are sorted into deciles based on their market beta calculated using daily returns in the past 12 months. To account for illiquidity and non-synchronous trading, we include on the right hand side of the regression equation five lags of the excess market return, in addition to the contemporaneous excess market return. The pre-ranking beta is simply the sum of the six coefficients from the OLS regression. CoBAR is the average pairwise partial return correlation in the low-beta decile measured in the ranking period. We begin our analysis in 1970, as that year was when the low-beta anomaly was first recognized by academics. The time series average of $C o B A R$ is 0.11 , and the autocorrelation in CoBAR is 0.1. 


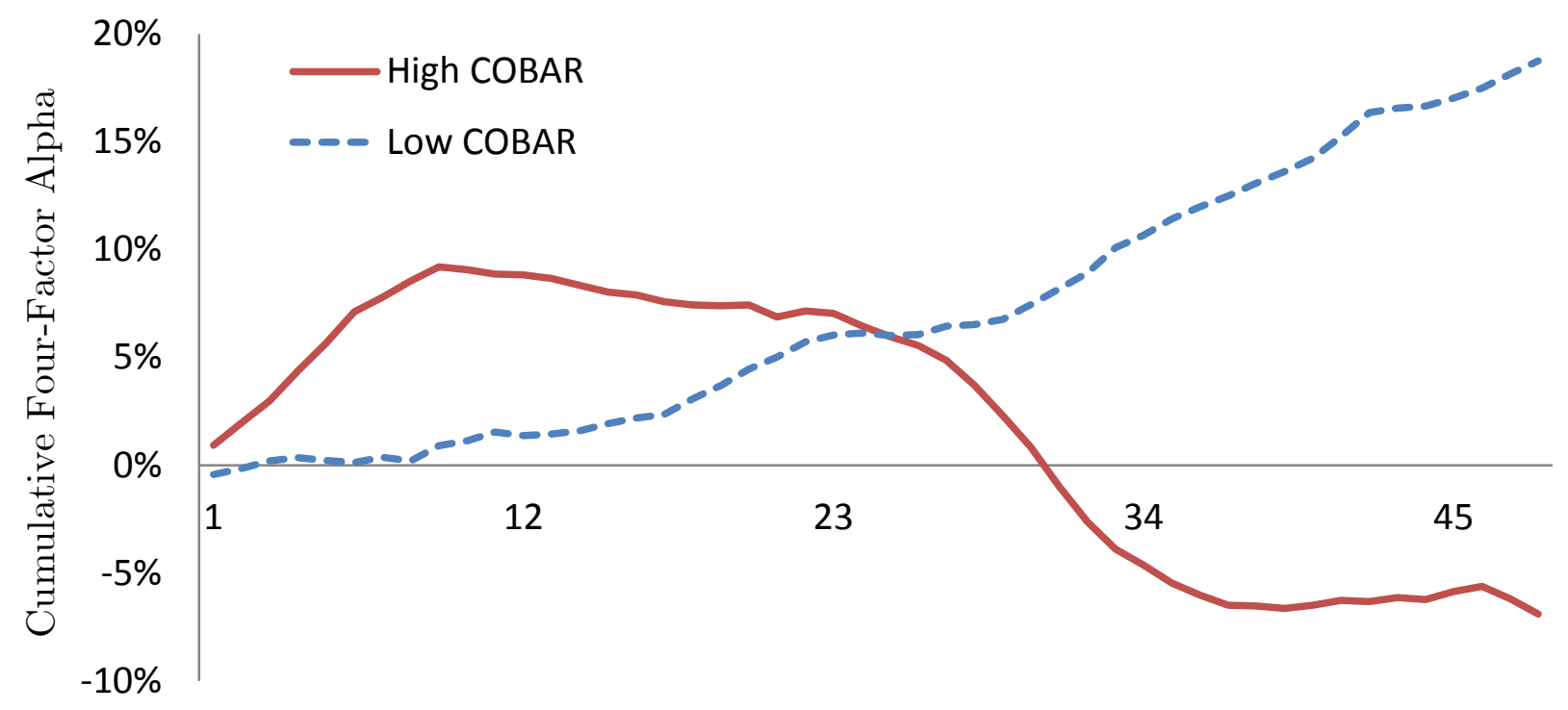

Figure 2: This figure shows returns to the beta arbitrage strategy as a function of lagged CoBAR. At the end of each month, all stocks are sorted into deciles based on their market beta calculated using daily returns in the past 12 months. To account for illiquidity and non-synchronous trading, we include on the right hand side of the regression equation five lags of the excess market return, in addition to the contemporaneous excess market return. The pre-ranking beta is simply the sum of the six coefficients from the OLS regression. All months are then sorted into five groups based on CoBAR, the average pairwise weekly three-factor residual correlation within the low-beta decile over the previous 12 months. The red curve shows the cumulative Carhart four-factor alpha to the beta arbitrage strategy (i.e., a portfolio that is long the value-weight low-beta decile and short the value-weighted high-beta decile) formed in high CoBAR periods, whereas the dotted blue curve shows the cumulative Carhart four-factor alpha to the beta arbitrage strategy formed in periods of low $C O B A R$. 

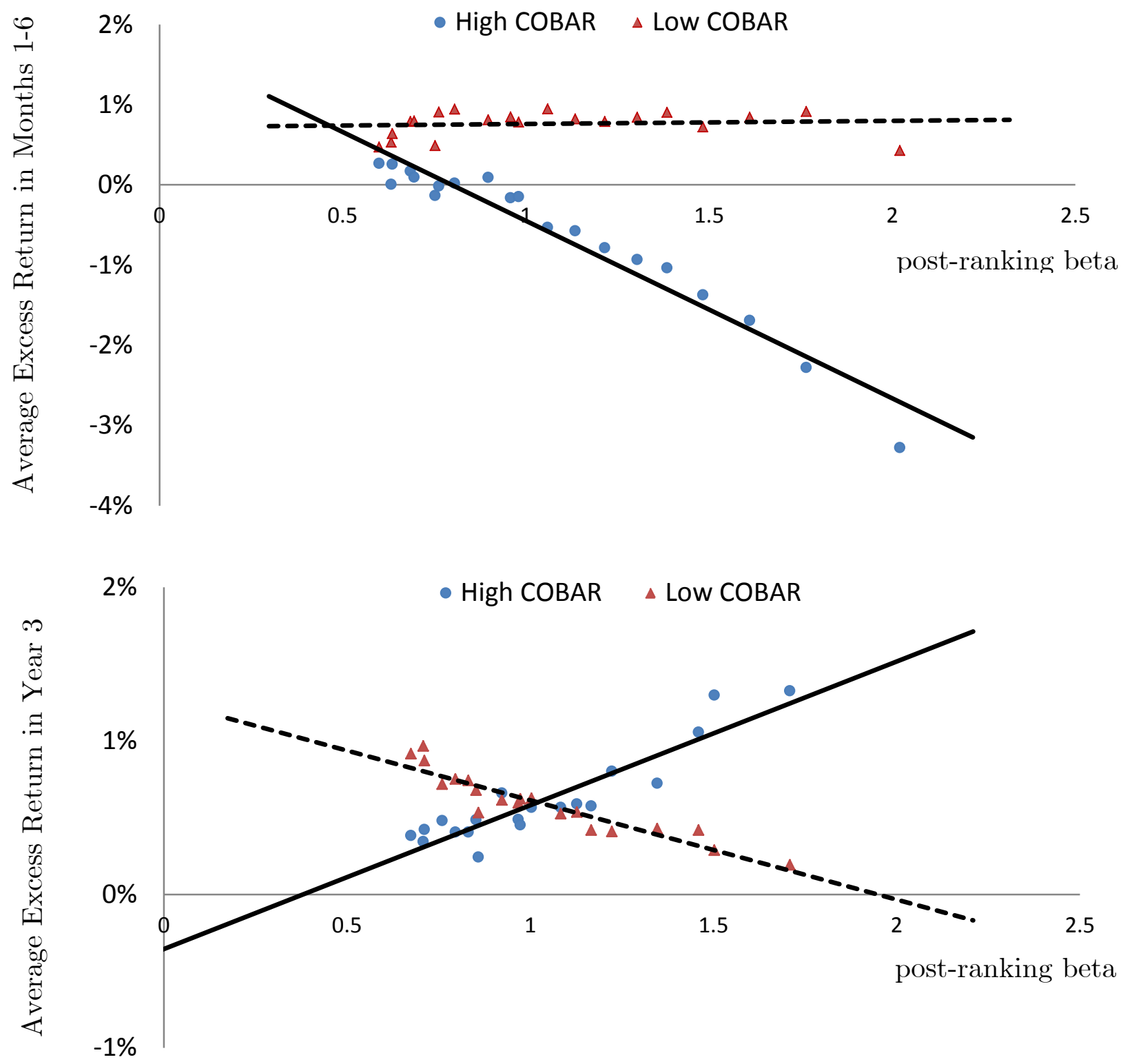

Figure 3: This figure shows the security market line as a function of lagged CoBAR. At the end of each month, all stocks are sorted into vigintiles based on their market beta calculated using daily returns in the past 12 months. To account for illiquidity and non-synchronous trading, we include on the right hand side of the regression equation five lags of the excess market return, in addition to the contemporaneous excess market return. The pre-ranking beta is simply the sum of the six coefficients from the OLS regression. We then estimate two security market lines based on these 20 portfolios formed in each period: one SML using portfolio returns in months 1-6, and the other using portfolio returns in year 3 after portfolio formation; the betas used in these SML regressions are the corresponding post-ranking betas. The Y-axis reports the average monthly excess returns to these 20 portfolios, and the $\mathrm{X}$-axis reports the post-ranking betas of these portfolios. Beta portfolios formed in high CoBAR periods are depicted with a blue circle and fitted with a solid line, and those formed in low $C o B A R$ periods are depicted with a red triangle and fitted with a dotted line. The top panel shows average excess returns and betas to the beta-arbitrage strategy in months 1-6 after portfolio formation, while the bottom panel shows average excess returns and betas in year 3 after portfolio formation. 


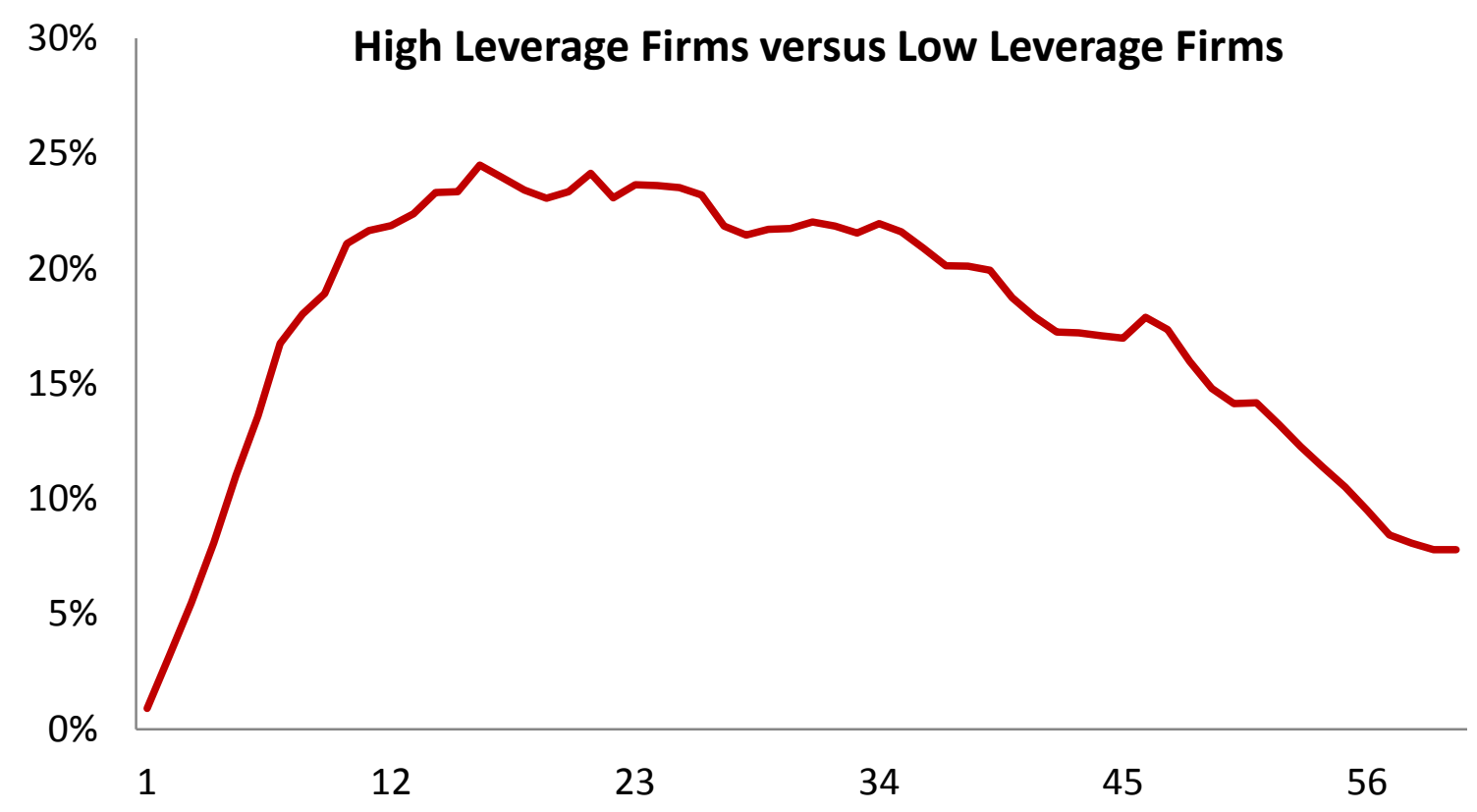

Figure 4: This figure shows how the relation between CoBAR and subsequent beta arbitrage returns varies with firm leverage. At the end of each month, all stocks are sorted into deciles based on their market beta calculated using daily returns in the past 12 months. To account for illiquidity and non-synchronous trading, we include on the right hand side of the regression equation five lags of the excess market return, in addition to the contemporaneous excess market return. The pre-ranking beta is simply the sum of the six coefficients from the OLS regression. All months are then sorted into five groups based on CoBAR, the average pairwise weekly three-factor residual correlation within the low-beta decile over the previous 12 months. At the beginning of the holding period, we sort stocks into four equal groups using book leverage. For each leverage quartile, we compute the CoBAR return spread - i.e., the difference in Carhart four-factor alpha to the beta arbitrage strategy (i.e., a portfolio that is long the value-weight low-beta decile and short the value-weighted high-beta decile) between high and low CoBAR periods. The solid red curve shows the cumulative difference in the $C O B A R$ return spread between the highest and lowest leverage quartiles over the five years after portfolio formation. This difference in the CoBAR return spread is $1.89 \% / \mathrm{month}$ (tstatistic $=3.29)$ in year one, and is $-0.55 \% /$ month $(\mathrm{t}$-statistic $=-2.19)$ in years three-five. 

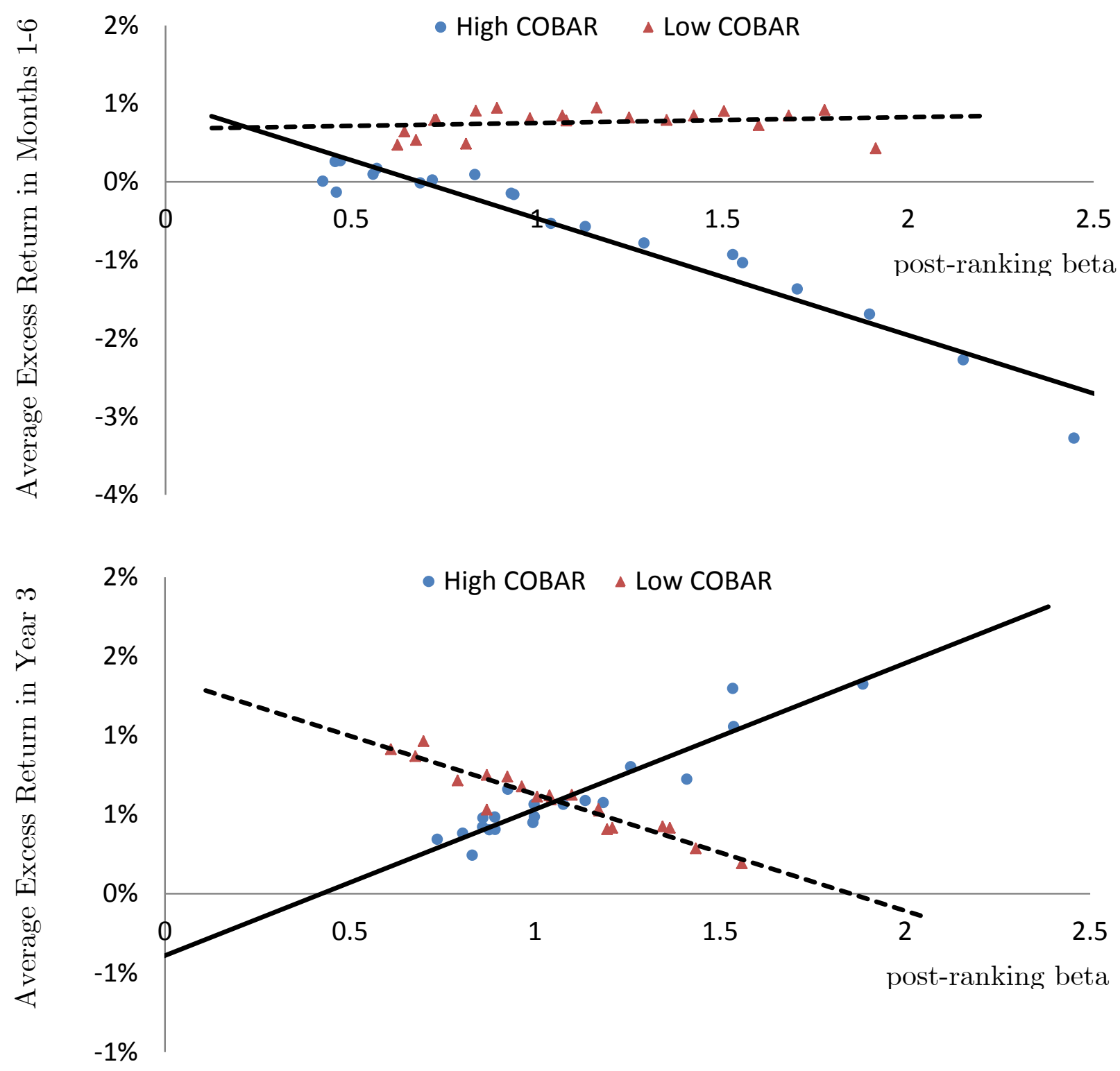

Figure 5: This figure shows the conditional security market line as a function of lagged CoBAR (i.e., where betas are allowed to vary with $C o B A R$ ). At the end of each month, all stocks are sorted into vigintiles based on their market beta calculated using daily returns in the past 12 months. To account for illiquidity and non-synchronous trading, we include on the right hand side of the regression equation five lags of the excess market return, in addition to the contemporaneous excess market return. The pre-ranking beta is simply the sum of the six coefficients from the OLS regression. We then estimate two conditional security market lines based on these 20 portfolios: one SML using portfolio returns in months 1-6, and the other using portfolio returns in year 3 after portfolio formation; the betas used in these SML regressions are the corresponding post-ranking betas. The Y-axis reports the average monthly excess returns to these 20 portfolios, and the $\mathrm{X}$-axis reports the post-ranking beta of these portfolios. Beta portfolios formed in high CoBAR periods are depicted with a blue circle and fitted with a solid line, and those formed in low CoBAR periods are depicted with a red triangle and fitted with a dotted line. The top panel shows average excess returns and betas to the beta arbitrage strategy in months 1-6 after portfolio formation, while the bottom panel shows average excess returns and betas in year 3 after portfolio formation. 


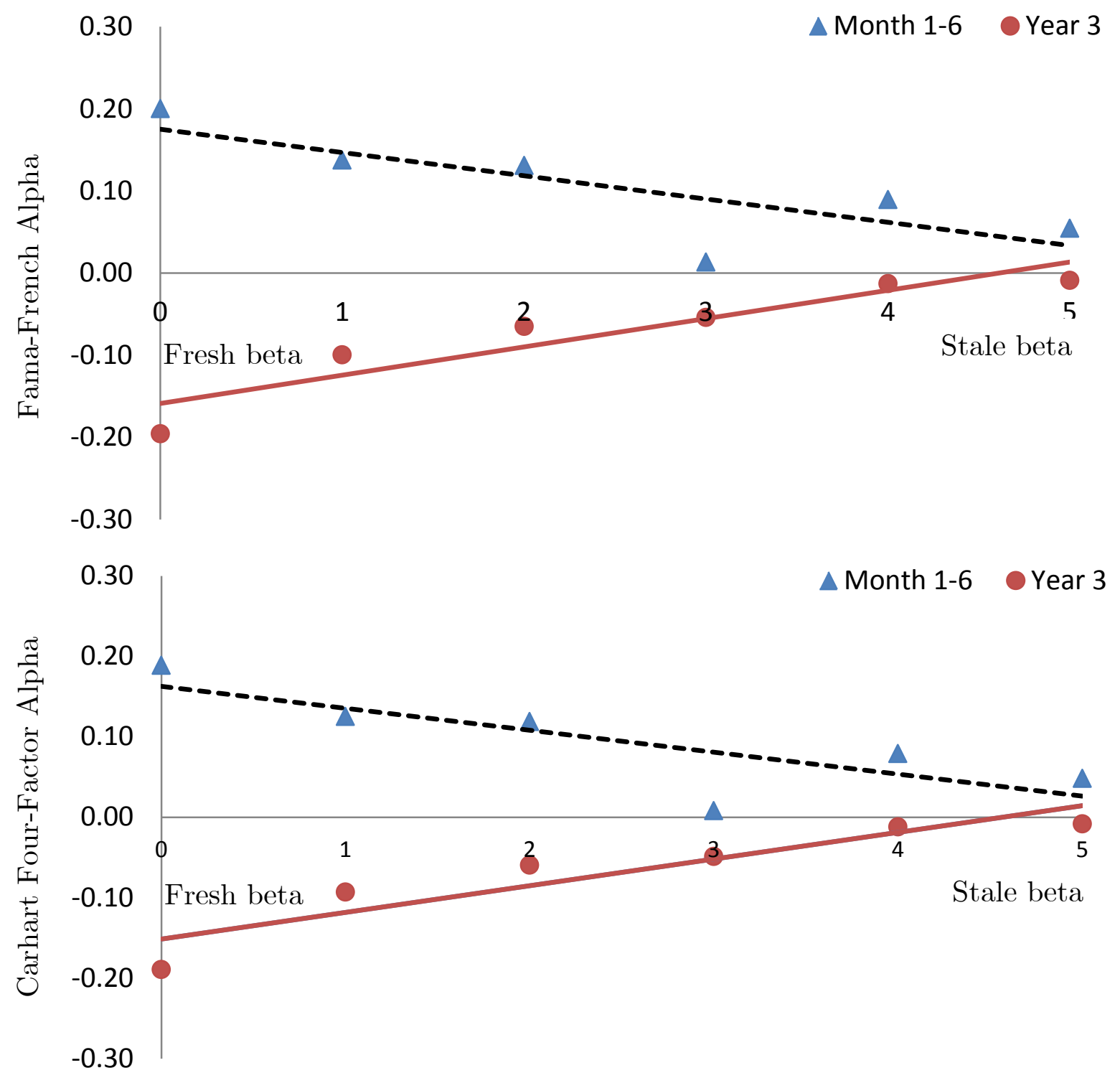

Figure 6: This figure shows how the information in CoBAR about time-variation in the expected holding and post-holding return to beta-arbitrage strategies decays as staler estimates of beta are used to form the beta-arbitrage strategy. At the end of each month, all stocks are sorted into deciles based on their market beta calculated using daily returns in the past 12 months. To account for illiquidity and non-synchronous trading, we include on the right hand side of the regression equation five lags of the excess market return, in addition to the contemporaneous excess market return. The pre-ranking beta is simply the sum of the six coefficients from the OLS regression. We then compute the strategy return as the value-weight low-beta decile return minus the value-weight high-beta decile return. We separately regress the abnormal return of the beta-arbitrage strategy in months one-six and year three on CoBAR. In this process, we first use a fresh estimate of beta, calculated using daily returns in the past 12 months. We then repeat the analysis using stale betas, computed from daily returns in each of the prior 5 years (thus having different beta portfolios as of time zero for each degree of beta staleness). We plot the corresponding regression coefficients (results for months 1-6 plotted with a blue square and results for year 3 plotted with a red circle) for each of the six beta-arbitrage strategies, ranging from fresh beta to five years stale beta. The top (bottom) panel reports results based on three-factor (four-factor) alpha. 